\title{
Peripheral taste detection in honey bees: What do taste receptors respond to?
}

\author{
Louise Bestea $^{1}$ (D) | Alexandre Réjaud ${ }^{2}$ ｜ Jean-Christophe Sandoz ${ }^{3}$ ｜ Julie Carcaud ${ }^{3}$ | \\ Martin Giurfa $^{1,4,5}$ (D) | Maria Gabriela de Brito Sanchez ${ }^{1}$ iD
}

${ }^{1}$ Research Centre on Animal Cognition, Center for Integrative Biology, CNRS (UMR 5169), University of Toulouse, Toulouse, France

${ }^{2}$ Laboratoire Evolution et Diversité Biologique, CNRS, IRD (UMR 5174), University of Toulouse, Toulouse, France

${ }^{3}$ Evolution, Genomes, Behavior and Ecology, CNRS, IRD (UMR 9191, University Paris Saclay, Gif-sur-Yvette, France

${ }^{4}$ College of Animal Sciences (College of Bee Science), Fujian Agriculture and Forestry University, Fuzhou, China

${ }^{5}$ Institut Universitaire de France (IUF), Paris, France

\section{Correspondence}

Maria Gabriela de Brito Sanchez, Research Center on Animal Cognition, Center for Integrative Biology, CNRS - University Paul Sabatier Toulouse III, 118 route de Narbonne, Toulouse 31062, France. Email: maria.de-brito-sanchez@univ-tlse3. fr

\section{Funding information}

Centre National de la Recherche Scientifique; Université Paul Sabatier; Institut Universitaire de France; Agence Nationale de la Recherche, Grant/Award Number: APITASTE ANR-18-CE37-0021

\begin{abstract}
Understanding the neural principles governing taste perception in species that bear economic importance or serve as research models for other sensory modalities constitutes a strategic goal. Such is the case of the honey bee (Apis mellifera), which is environmentally and socioeconomically important, given its crucial role as pollinator agent in agricultural landscapes and which has served as a traditional model for visual and olfactory neurosciences and for research on communication, navigation, and learning and memory. Here we review the current knowledge on honey bee gustatory receptors to provide an integrative view of peripheral taste detection in this insect, highlighting specificities and commonalities with other insect species. We describe behavioral and electrophysiological responses to several tastant categories and relate these responses, whenever possible, to known molecular receptor mechanisms. Overall, we adopted an evolutionary and comparative perspective to understand the neural principles of honey bee taste and define key questions that should be answered in future gustatory research centered on this insect.
\end{abstract}

\section{K E Y W O R D S}

Apis mellifera, gustation, gustatory receptors, honey bee

\footnotetext{
Martin Giurfa and Maria Gabriela de Brito Sanchez senior authorship shared.

Edited by: Giovanni Galizia
}

๔ 2021 Federation of European Neuroscience Societies and John Wiley \& Sons Ltd 


\section{1 | INTRODUCTION}

Taste, the sense by which chemical substances are perceived when they are brought into contact with gustatory chemoreceptors, allows discriminating edible from non-edible items based on multiple characteristics such as the nature of the taste experienced, its hedonic and nutritional value, and its toxicity, among others. It is, therefore, crucial for survival not only because it participates in the regulation of energy budgets through the consumption of food but also because it mediates other functions such as the regulation of $\mathrm{pH}$ and water-saline balance via electrolyte detection and consumption. In insects, taste perception occurs via the contact of gustatory substances with chemoreceptors, which are hosted within specialized hairs termed sensilla or bristles (Nayak \& Singh, 1983; Stocker, 1994) located on chemosensory organs (see reviews in de Brito Sanchez \& Giurfa, 2011; Liman et al., 2014; Scott, 2018; Stocker, 2004; Vosshall \& Stocker, 2007). The organs related to taste perception are mainly the antennae, the mouthpieces, the tarsi, and the margins of the wings, although sensilla containing chemoreceptors may also be found in other regions of the body, such as the ovipositor or on the body surface itself, enhancing thereby the possibility of gustatory contact (Scott, 2018; Stocker, 1994; Figure 1a).
These sensilla are cuticular evaginations with a characteristic aperture at their apex (Figure 1b). By being located on different body organs, gustatory sensilla may participate in several behavioral contexts, from food and oviposition-site detection (Sollai et al., 2018; Sollai \& Crnjar, 2019) to nestmate and sexual recognition (Meunier et al., 2000; Starostina et al., 2012; Stoffolano et al., 1997), among others.

Chemoreceptor neurons-termed gustatory receptor neurons (GRNs) - are hosted within sensilla and are tuned to detect different types of tastants based on the different types of molecular receptors they may express in their dendritic membrane. Chemical substances enter into the sensillum through the pore and reach the dendrites of the GRNs, which bathe into a receptor hemolymph. This hemolymph is enclosed by surrounding cells and differs in electrolytic composition from the hemolymph circulating in the insect body (Kaissling \& Thorson, 1980). In lepidopterans, the sensilla hosting GRNs are termed sensilla styloconica and are located on the maxilla, although other gustatory sensilla can be located on the ventral side of the labrum. Sensilla styloconica have four gustatory GRNs and one mechanosensory neuron (Agnihotri et al., 2016; $\mathrm{Xu}, 2020)$. GRNs respond with specific activity patterns to plant tastants such as sugar and amino acids, which

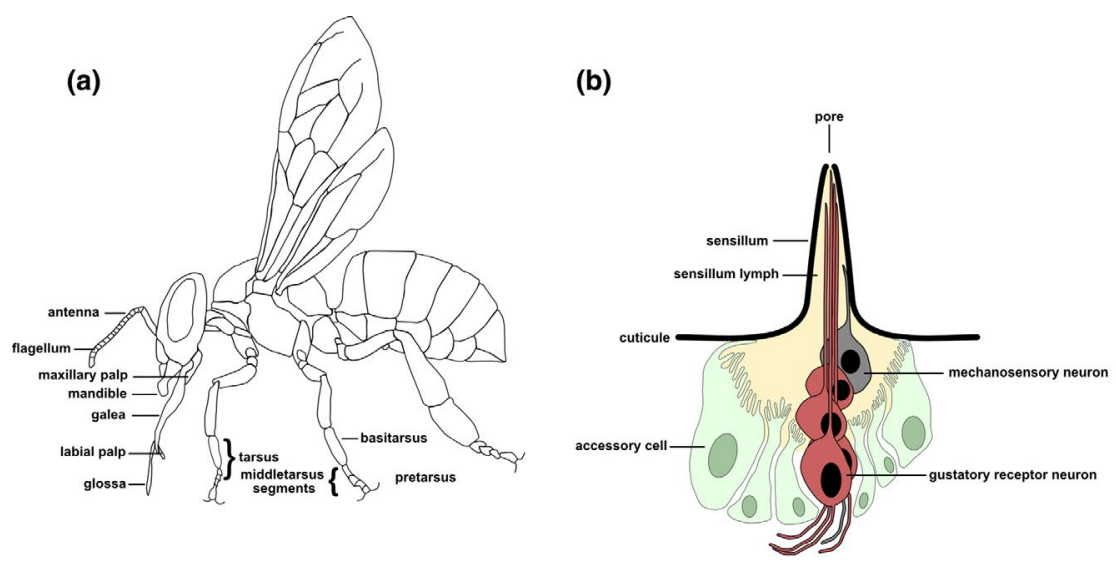

(c)

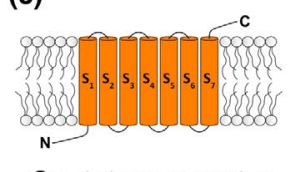

Gustatory receptor

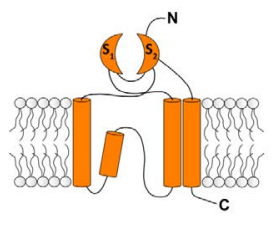

Ionotropic receptor
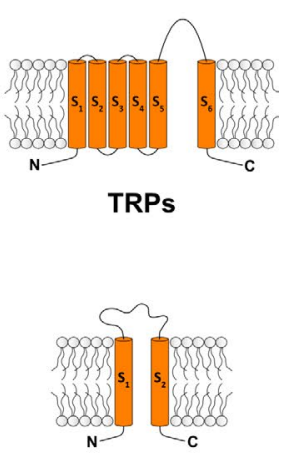

Pickpocket 28

F I G U RE 1 Honey bee taste, from body appendages to molecular taste receptors. (a) Anatomy of the honeybee. The main chemosensory organs involved in taste perception (antennae, mouthparts, and tarsal regions of the legs) are indicated. They bear gustatory sensilla, which are hair-like structures hosting gustatory receptor neurons. From de Brito Sanchez, 2011. (b) Schematic of a chaetic gustatory sensillum. Four gustatory receptor neurons (in purple) bathing in a cavity defined by auxiliary sensillar cells (in green) and filled with sensillum receptor hemolymph (in yellow) extend their dendrites toward the apex of the cuticular hair. A mechanoreceptor neuron (in gray) is attached to the basal wall of the hair. Tastants penetrate into the sensillum through a pore at the apex and stimulate molecular taste receptors located in the neuron membrane. (c) Four families of molecular taste receptors in insects. Schematics of gustatory receptors (GRs), ionotropic receptors (IRs), TRP transient receptor potential (TRP), and pickpocket (PPK) channels 28. In all schemes, the space above the lipid membrane represents the extracellular domain and that below the intracellular, cytosolic domain. The GR shown has seven (S1-S7) transmembrane domains, an extracellular C-terminal tail, and a cytosolic N-terminal region. The TRP channel shown corresponds to the TRPA1 protein in which four identical or similar subunits with six transmembrane domains $\left(\mathrm{S}_{1}-\mathrm{S}_{6}\right)$, and cytosolic $\mathrm{N}$ - and $\mathrm{C}$-terminal tails are combined to form a functional channel. The IR shown has an extracellular N-terminal tail, a bipartite ligand-binding domain whose two halves $\left(\mathrm{S}_{1}\right.$ and $\left.\mathrm{S}_{2}\right)$ are separated by an ion channel domain, and a short cytoplasmic C-terminal region. PPK 28 belongs to the Degenerin/Epithelial sodium channel family (Deg/ENaC) in which each channel comprises three subunits (or multiples of three), and each subunit comprises two transmembrane domains $\left(\mathrm{S}_{1}\right.$ and $\left.\mathrm{S}_{2}\right)$, two cytosolic $\mathrm{N}$ - and C- terminal tails and an unusually large and highly structured extracellular domain. Adapted from Scott, 2018 
promote feeding, and to deterrent, bitter substances, which mediate food rejection (Schoonhoven \& Loon, 2002). In the fruit fly Drosophila melanogaster, the insect whose taste has been most thoroughly studied in the last decades owing to the availability of neurogenetic tools and, which sets, therefore, a standard for comparisons, short, intermediate and long taste sensilla subtypes have been described. Each subtype contains one mechanosensory neuron and either two (intermediate sensilla) or four (short and long sensilla) GRNs (Hiroi et al., 2002). From the two GRNs located within intermediate sensilla, one responds to both sugars and low-salt concentrations, which are attractive for flies, while the other responds to bitter substances and high-salt concentrations, which are aversive (Hiroi et al., 2004). Short sensilla host a sugar-sensitive GRN (Hiroi et al., 2002, 2004), a water-sensitive GRN (Cameron et al., 2010; Chen et al., 2010; Dahanukar et al., 2007; Hiroi et al., 2002, 2004; Meunier et al., 2003; Weiss et al., 2011), a low salt-sensitive GRN (Meunier et al., 2003), and a bitter-sensitive GRN (Dahanukar et al., 2007; Hiroi et al., 2002; Weiss et al., 2011). Long sensilla host a sugarsensitive GRN, a water-sensitive GRN, a low salt-sensitive GRN, and a high salt-sensitive GRN but no bitter-sensitive GRN (Hiroi et al., 2002; Weiss et al., 2011). GRNs convey, therefore, taste-specific information that is further processed in central regions of the insect brain such as the subesophageal zone (SEZ), which receives afferences from GRNs located at the level of the mouthpieces and antennae (Thorne et al., 2004; Wang et al., 2004).

The gustatory specificity of a GRN is conferred by various types of molecular gustatory receptors (GRs) located in the GRN membrane (Figure 1c). One family of GRs includes heptahelical transmembrane proteins termed GRs (Clyne et al., 2000; Dunipace et al., 2001; Scott et al., 2001). Tastant molecules that penetrate into a gustatory sensillum bind to these proteins triggering a transduction process resulting in neural activation (Figure 1c). GRs are encoded by gustatory receptor genes $(G r s)$. The genes are given the name " $G r$ " (gustatory receptor) and are differentiated by a number added after the $G r$ prefix. This number is also extensive to the GRs they encode.

Most of the GRs tuned to bitter and sweet tastants in flies, and other insects are thought to form ligand-gated ion channels (Sato et al., 2011), differently from mammals where G protein-coupled receptors (GPCR) confer the molecular taste specificity to taste receptor cells. This difference indicates that mammals and insects detect the same classes of chemicals using taste receptors cells that are evolutionary distinct (Liman et al., 2014). However, GPCR signaling cascades are also involved in the fly gustatory system (Clyne et al., 2000), possibly acting in parallel to GR pathways, enhancing the response to low concentrations of ligands, and/or modulating the activity of GRs through phosphorylation (Liman et al., 2014).
Besides GRs, other families of molecular receptors allow detecting tastants in insects. Among them, ionotropic receptors (IRs), which differ from GRs in both their functional principle and gustatory tuning, are involved in chemosensation (olfaction and gustation) and have been characterized in the GRNs of insects (Benton et al., 2009; Koh et al., 2014; Zhang et al., 2013; Figure 1c). IRs are more ancient than GRs and have evolved from ionotropic glutamate receptors (iGluRs; Benton et al., 2009; Croset et al., 2010; Rytz et al., 2013). They function as ligand-gated ion channels (Benton et al., 2009; Croset et al., 2010) but do not belong to the well-described kainate, $\alpha$-amino-3-hydroxy-5-methyl-4-isoxazolepropionic acid (AMPA) or $N$-methyl-D-aspartate (NMDA) receptor classes of iGluRs and have divergent ligand-binding domains that lack their characteristic glutamate-interacting residues. In the fruit fly, IRs form multimodal receptors mediating the perception of odors, tastes, or other sensory cues such as humidity or temperature. Their role in taste perception has been well documented in D. melanogaster in the case of salt, amino acid, and acetic acid detection (Ganguly et al., 2017; Jaeger et al., 2018; Rimal et al., 2019; Zhang et al., 2013). Some IRs, as for instance those belonging to the IR20a clade (35 IRs), are expressed in GRNs (Koh et al., 2014), and at least four other IRs are expressed in gustatory organs such as the labellum and the pharynx (Croset et al., 2010; Zhang et al., 2013). One of these IRs, IR76b, acts as a sensor of low salts (Zhang et al., 2013) and amino acids if it is co-expressed with IR20a (Croset et al., 2016; Ganguly et al., 2017). In addition, interactions between GRNS expressing IRs and GRNs expressing GRs have been observed in the fly for the case of salt sensing. It was shown, for instance, that fly attraction to low-salt concentrations depends primarily on sweet-sensing GRNs expressing GR64f, with additional input from neurons expressing IR94e (Jaeger et al., 2018). Overall, these studies indicate that in D. melanogaster IRs can function as molecular taste receptors (yet also as olfactory receptors) and mediate behavioral reactions to tastants in the environment (Rimal \& Lee, 2018).

In addition to GRs and IRs, TRP (Transient Receptor Potential) channels have been identified as additional actors of peripheral taste detection (Figure 1c). These proteins belong to a superfamily of cation transmembrane proteins expressed in many sensory neurons and respond to a wide range of sensory stimuli. They play a role in sensory signaling in multiple behavioral contexts such as phototaxis, thermotaxis, and gravitaxis and also participate in taste detection. In $D$. melanogaster and in the moth Manduca sexta, for instance, the TRPA 1 channel is required for the detection of aversive tastants such as aristolochic acid in a way that is independent of GR detection (Afroz et al., 2013; Kim et al., 2010).

Another receptor gene family with a gustatory role has been identified in the fruit fly. The amiloride-sensitive DEG/eNaC (degenerin/epithelial sodium channel) channels 
(Kellenberger \& Schild, 2002), which are known as pickpocket (PPK) channels (Adams et al., 1998; Liu et al., 2003), participate in multiple sensory (Ben-Shahar, 2011), including water sensation and salt taste. Individual $\mathrm{ENaC}$ subunits associate as homomultimer or heteromultimer to form voltage insensitive, amiloride-sensitive sodium channels. Thirty-one members of the PPK family were identified in Drosophila, each representing a channel subunit (Ben-Shahar, 2011). One of them, the PPK28 channel, was shown to serve as the osmolarity sensor for gustatory water reception in the adult fruit fly (Chen et al., 2010; Figure 1c). In addition, PPK11 or PPK19 is expressed in gustatory organs and mediate responses to low-salt and high-salt concentrations in the larva of Drosophila (Alves et al., 2014; Liu et al., 2003) and to high-salt concentrations in adult flies (Liu et al., 2003). Other PPK channels could participate in modulating the detection of other tastes (e.g., salts) in the GRNs that express them.

To what extent the various molecular mechanisms are shared across insect species remains to be determined. The vast majority of studies on the molecular underpinnings of peripheral taste detection have been performed in the fruit fly, which provides an unmatched array of neurogenetic tools for addressing the specific roles of single neurons and receptors in perceptual phenomena. Yet uncovering these mechanisms in other insect species, in particular in those that bear economic importance or serve as models for other research areas, constitutes an important strategic goal. Such is the case of the honey bee (Apis mellifera), which has a fundamental environmental and socioeconomic importance given its crucial role as pollinator agent in agricultural landscapes and which has served as a traditional model for basic research on various sensory modalities (e.g., visual [Avarguès-Weber et al., 2011; Avarguès-Weber et al., 2012] olfactory [Paoli \& Galizia, 2021; Sandoz, 2011], mechanosensory [Giurfa \& Malun, 2004; Scheiner et al., 2005]). In the last decade, massive colony losses have been reported worldwide and described as the "colony collapse disorder" (Oldroyd, 2007; VanEngelsdorp et al., 2009). This dramatic decrease in honey bee populations may have multiple causes such as an uncontrolled use of pesticides (Goulson, 2013; Pisa et al., 2014 Sanchez-Bayo \& Goka, 2014); the presence of parasites, predators, and diseases; and the reduction of natural habitats and biodiversity through intensive agricultural practices and monocultures (Brown \& Paxton, 2009; Goulson et al., 2008, 2015). In addition, different forms of environmental pollution may also contribute to colony losses (Burden et al., 2019; Negri et al., 2015; Søvik et al., 2015). In this context, understanding the basic principles of honey bee taste is important to determine the capacity of this insect to detect and avoid potential noxious substances (e.g., pesticides and pollutants) present in the environment.

Here we review the current knowledge on honey bee GRs to provide an integrative view of honey bee peripheral taste detection. We describe behavioral and electrophysiological responses to several tastant categories and relate these responses, whenever possible, to known molecular receptor mechanisms. Overall, we adopted an evolutionary and comparative perspective to understand the neural principles of honey bee taste and define key questions that should be answered in gustatory research centered on this insect.

\section{2 | THE GUSTATORY WORLD OF HONEY BEES}

Despite their strategic importance, studies on the gustatory sense of honey bees remain scarce (de Brito Sanchez, 2011). Yet taste plays an important role throughout the different life stages of the honey bee. From the larval to the forager stage, detecting and responding appropriately to substances according to their nutritional values is crucial for individual and colony survival. This is particularly important for adult bees (typically 3-week-old bees), which after reaching the foraging stage are in charge of collecting nectar and pollen as sources of carbohydrates (e.g., sucrose, fructose, and glucose) and proteins, respectively. Foragers need, therefore, to be sensitive to these and other substances present in lower quantities in flowers such as amino acids, vitamins, or mineral salts (de Brito Sanchez, 2011; Harborne, 1994). Some bees may also collect water with saline content and resins (Drescher et al., 2019) to produce propolis, thus being exposed to different, additional tastes. These multiple foraging specializations suggest that the gustatory world of bees may include a relatively large spectrum of tastants (sugars, salts and amino acids) present in the natural products they choose and collect.

\section{1 | Behavioral responses to sugars}

Free-flying bees are responsive to sugars present in nectar and honeydew. The most impressive survey on honey bees' behavioral responses to tastants that are perceived as sweet by humans was performed by Nobel Prize winner Karl von Frisch, who quantified the choice of free-flying bees confronted with solutions of 34 different tastants offered in small dishes (von Frisch, 1934; Figure 2a). ${ }^{1}$ Using 1-M sucrose solution as a reference (i.e., the solution to which foragers was trained), he determined that, besides sucrose, eight other substances are sweet for the bees: maltose, melezitose, glucose, fructose, trehalose, $\alpha$-methyl glucoside, fructose, and inositol.

\footnotetext{
${ }^{1}$ Von Frisch's works on honey bee taste can be found in this impressive 156-page article, which is unfortunately mostly ignored by modern research on insect taste, probably because it is only available in German and because von Frisch himself included only a brief summary of these investigations at the end of the book that serves as reference for his life work (von Frisch, 1967). Yet his work on bee taste covered multiple taste modalities and proposed several hypotheses that were later verified or proposed again, ignoring his original statements.
} 
(a)
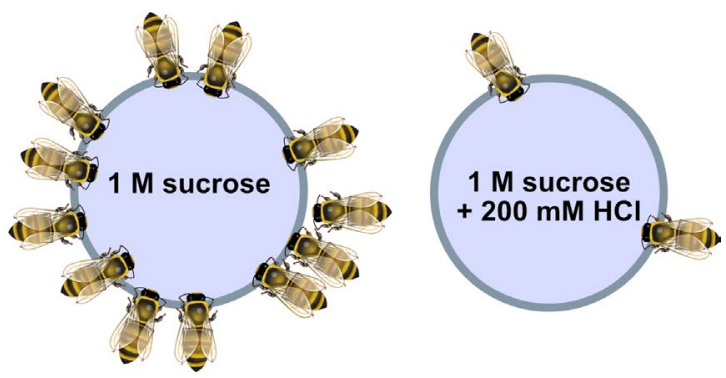

(b)

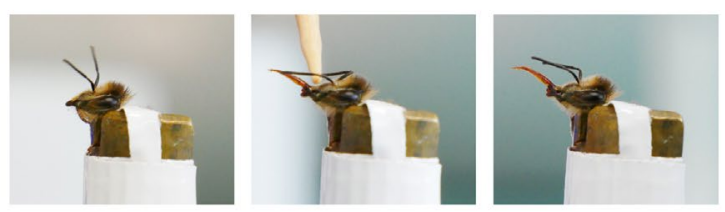

(c)

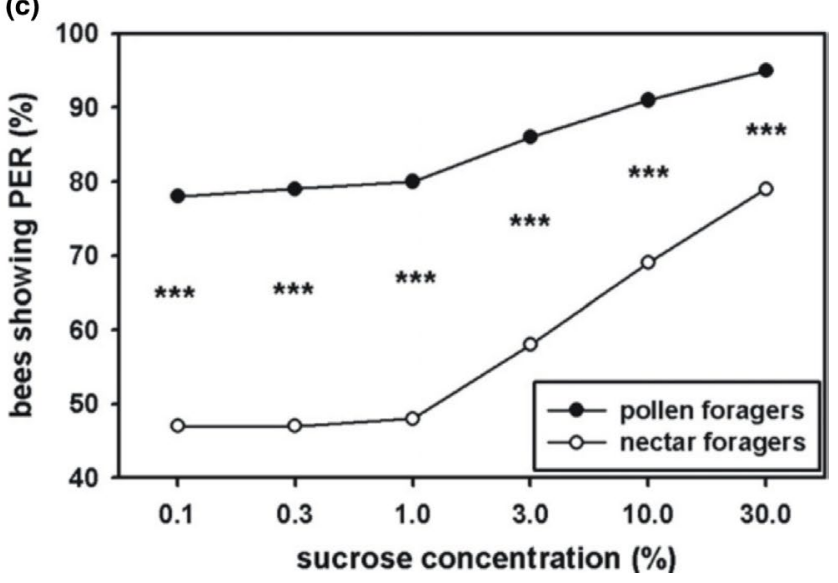

F I G URE 2 Behavioral methods for studying gustatory responses of honey bees in an appetitive context. (a) Choice of tastant solutions by free flying foragers. This procedure involves training free-flying bees to collect sucrose solution (e.g., $1 \mathrm{M}$ ) on a feeder or dish and then confronting them with the original appetitive solution versus the same solution to which a different tastant was added (e.g., 200-mM HCl). In this schema, foragers prefer the 1-M sucrose solution over a mixture of 1-M sucrose and 200-Mm HCl. Adapted from von Frisch, 1934. (b) A bee harnessed within a cylindrical tube before, during, and after antennal stimulation with a toothpick soaked in a sucrose solution. Contact of sucrose receptor neurons on the antennae with sucrose and other sweet tastants triggers the Proboscis Extension Reflex (PER), which is an appetitive response to food. (c) Sucrose-responsiveness curves of harnessed pollen and nectar foragers. Individual foragers prepared as in (b) were tested for their responsiveness (PER) to six increasing sucrose concentrations ranging from $0.1 \%$ to $30 \%$ (w/w). Upon each antennal stimulation with sucrose, the occurrence of PER was noted. A significantly higher percentage of pollen foragers responded with PER to each sucrose stimulation than nectar foragers, thus showing that nectar foragers are more selective and respond mainly to concentrated sucrose solutions (***: statistically significant difference). From Scheiner et al. (2004)

Twenty-five tastants (including sorbitol, mannitol, $l$ - and $d$ arabinose, xylose, sorbose, and raffinose) that we perceive as sweet are unsweet for the bees. In other behavioral experiments performed with free-flying bees, sucrose was preferred over glucose, glucose over maltose, and maltose over fructose (Wykes, 1952) or sucrose over fructose and fructose over glucose (Waller, 1972). In other experiments with harnessed bees tested for their appetitive proboscis extension response (or PER), which is triggered by stimulation of the antennae with an appetitive stimulus (Figure 2b), fructose, and sucrose were ranked either equally (Miriyala et al., 2018) or, as in freeflying bees, sucrose was preferred to fructose (Bachman \& Waller, 1977). A mixture of equal parts of sucrose, glucose, and fructose was reported to be less attractive than sucrose or a mixture in which sucrose was dominant (Bachman \& Waller, 1977). Furthermore, sucrose solution was preferred over dry sugar, which requires the additional effort of dissolving the sugar for collection (Liao et al., 2020).

The responsiveness of bees toward sweet solutions may vary significantly between individuals of the same colony and is highly conditioned by internal (hunger and physiological state, genetics, age, task specialization, e.g., Figure 2c) as well as by external factors (season and weather, colony reserves, presence of brood, etc.; Scheiner et al., 2004). For instance, nectar foragers are more selective and respond mostly to the highest sucrose concentrations, while pollen foragers are less selective and respond to a broader range of sucrose solutions, including the more diluted ones (Page \& Erber, 2002). Variability in sucrose responsiveness is considered a key element for division of labor and social organization within the colony: it reflects the existence of different thresholds of responsiveness for an appetitive stimulus and thus predisposes certain individuals to perform certain tasks (e.g., nectar collection) for the society (Bonabeau et al., 1996). Interindividual differences in sucrose responsiveness depend on genetic factors, among others (Junca et al., 2019; Scheiner $\&$ Arnold, 2010). These interindividual differences are important as they may explain contradictory results concerning sugar preferences or the acceptance of sucrose solutions contaminated with agrochemicals (Arce et al., 2018; Kessler et al., 2015; Muth et al., 2020).

\section{2 | Behavioral responses to amino acids}

Amino acids are common constituents of floral nectars and critical components in the diets of insect pollinators. Detecting amino acids is important as pollen consumption during early adulthood shapes amino acid levels in the bee brain, which may affect development (de Groot, 1952), neural circuitry, and behavior (Gage et al., 2020). In addition, dietary amino acids confer immunity and increased resistance to parasites such as Nosema ceranae (Glavinic et al., 2017).

Using his behavioral assay involving free-flying bees, von Frisch (1934) tested the response of bees to $d$ - and $l$-valine, $d$-alanine, and glycine. He did not study if bees can detect these substances per se but rather focused on their effects on 
sucrose solution acceptance. He reported a decrease in acceptance after adding these amino acids to sucrose solution, but he did not report the concentrations of amino acids used in his experiments. Later works showed that honey bees detect amino acids in pollen (Harborne, 1994) and prefer pollens enriched in essential amino acids that are required by bees (valine, leucine, and isoleucine; Cook et al., 2003). They also prefer and are more responsive to sucrose solutions that contain amino acids such as glycine (Kim \& Smith, 2000) or proline and alanine (Bertazzini et al., 2010), which contradicts in part (at least for glycine) von Frisch's original report (1934). However, preference in these works depended on in the amino acid concentrations used, which may explain the contradictory results, besides differences in experimental methods.

In olfactory conditioning experiments, in which harnessed bees are trained to associate an odorant with a reward of sucrose solution delivered to the antennae and then to the proboscis (olfactory conditioning of the proboscis extension response or PER; Bitterman et al., 1983; Giurfa \& Sandoz, 2012), the addition of glycine to the sucrose solution improved learning (Kim \& Smith, 2000). This indicates that this amino acid enhances the appetitive value of the food reward. Preference for diets rich in amino acid contents may, however, vary with factors such as age and task specialization: when bees make the transition from within-hive duties to foraging, their nutritional needs shift toward a diet largely composed of carbohydrates at the expense of amino acid contents (Paoli et al., 2014).

\section{3 | Behavioral responses to bitter substances}

Honey bees may be exposed to bitter substances during foraging as some flowers produce nectars enriched in caffeine or nicotine (Liu et al., 2004; Singaravelan et al., 2005). The sensitivity of bees to nectars containing bitter substances is variable as some reports indicate that nectars containing them in higher concentrations can be deterrent (Johnson et al., 2006) while they can be attractive if the content of bitter substances is low (Singaravelan et al., 2005). Whether or not bees perceive bitter substances as distasteful is controversial as several works, including the pioneering experiments by von Frisch (1934), concluded to a remarkable lack of sensitivity of bees to these substances (see also Ayestaran et al., 2010), while other works reported that bees reject sucrose solution containing bitter substances based on the unpleasant nature of these substances (Mustard et al., 2012; Wright et al., 2010, 2013).

Von Frisch indicated that the sensitivity of bees to tastants that are bitter to humans was surprisingly low: "...bees are much less sensitive to bitter substances than we...it is possible to contaminate sugar with a bitter substance that does not interfere with its being taken up by bees but that renders it unacceptable to man." (von Frisch, 1967). Similar statements can be found in von Frisch's original work (1934), where he verified the relative lack of sensitivity of bees for substances such as quinine, salicin, and arbutin. In behavioral experiments in which harnessed bees were offered pure bitter solutions, the insects readily consumed the solutions (Ayestaran et al., 2010), consistently with von Frisch's original observations (von Frisch, 1934), even if ingestion resulted in high mortality. Similarly, conditioning experiments in which bees had to associate a tastant stimulation presented on the antennae with an electric shock (gustatory conditioning of the sting extension response or SER; Figure 3a) showed that bees were unable to learn the difference between distilled water and quinine or salicin, thus suggesting a lack of specific bitter perception, at least at the antennal level (Guiraud et al., 2018).

The rejection of sucrose solution containing bitter substances reported in some works could either be due to the presence of bitter tuned receptors or to an inhibitory effect of bitter substances on sucrose receptors. Several bitter tastants inhibit the firing of sweet-responding GRNs in bees and other insects (de Brito Sanchez et al., 2005, 2014; French et al., 2015; Jørgensen et al., 2007; Liscia \& Solari, 2000; Meunier et al., 2003). In the latter case, rather than inducing direct deterrence, bitter substances would degrade the perceived quality of the sucrose solution rendering it inacceptable because of the mismatch between a forager's expectation and the taste of an aqueous solution for which sweet taste has been degraded. Under this assumption, decreased responses to sucrose solutions supplemented with bitter tastants should be analyzed cautiously (Mustard et al., 2012; Wright et al., 2010, 2013) as such a decrease may not reflect aversion but a decrease in appetitive motivation upon stimulation with a denatured sucrose solution.

The same arguments could be applied to rejection responses of freely moving bees to pure bitter substances when these bees have been previously trained to fly to a feeding place to obtain an appetitive sucrose reward. The rejection of pure bitter substances delivered as punishment upon incorrect choices could again reflect the mismatch between the appetitive expectation of the trained bee and the sensing of a non-sugary solution. This could have been the case, for instance, in visual discrimination experiments in which bees were trained to distinguish similar colors using sucrose as reward and a $60-\mathrm{mM}$ quinine solution as punishment upon incorrect choices (Avarguès-Weber et al., 2010); in this case, the presence of quinine improved the discrimination of similar but not of dissimilar colors but the reasons for this improvement remain unclear.

The experimental conditions under which the bees are studied, that is, the possibility for them to express or not food rejection (de Brito Sanchez et al., 2015; Desmedt 
(a)

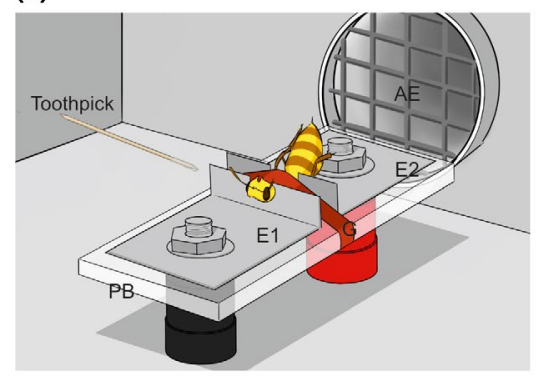

(b)

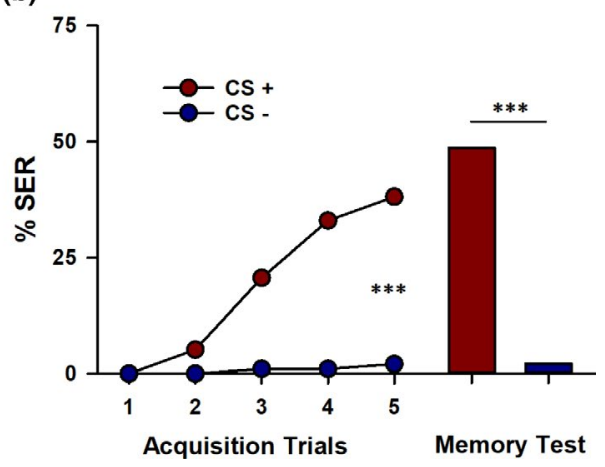

F I G U RE 3 Behavioral methods for studying the gustatory responses of honey bees in an aversive context. (a) Associative gustatory conditioning of the sting extension reflex (SER) in honeybees. In this aversive conditioning, bees learn to associate a taste stimulus given on one antenna by means of a toothpick with a mild electric shock and a different taste applied on the opposite antenna by means of a different toothpick with the absence of shock. The bee is fixed between two brass plates (E1, E2) set on a Plexiglas basis (PB) by a girdle (G) that clamps the thorax to restrain mobility. The bee closes a circuit and receives a mild electric shock (7.5 V) which induces the sting extension reflex (SER). Odor contamination is avoided via an air extractor (AE) placed behind the bee. Aversive learning results in SER to the punished tastant but not to the unpunished tastant. From Guiraud et al. (2018). (b) Differential conditioning of $1 \mathrm{M}$ sucrose versus $3 \mathrm{M} \mathrm{NaCl}$. One group of bees had sucrose associated with shock and $\mathrm{NaCl}$ without shock while another group had the reversed contingencies. No differences were detected between both groups and performances were pooled and represented as a CS+ (tastant punished) versus a CS- (tastant non-punished) discrimination. The graph shows conditioned responses (\% of bees exhibiting the sting extension reflex or SER to the punished tastant) along five CS+ and five CSacquisition trials and in a memory test performed $1 \mathrm{hr}$ after conditioning. Bees learned the gustatory discrimination and responded significantly more with a SER to the punished tastant than to the non-punished one at the end of training. One hour after conditioning, they remembered the learned associations. From Guiraud et al. (2018)

et al., 2016), seem determinant for measuring an enhanced or reduced aversive effect. For instance, when bees can choose between sucrose solution and sucrose solution spiked with a bitter substance, they prefer the pure sucrose solution and reject the mixture (Desmedt et al., 2016). Yet when bees are presented with a single feeding option and their escape possibilities are reduced, they consume the previously rejected mixture. This change in feeding behavior was interpreted as a case of feeding helplessness, in which bees behave as if they could not avoid the non-palatable food and consumed it (Desmedt et al., 2016). Similarly, in olfactory-learning experiments in which bees were trained to discriminate an odorant rewarded with sucrose from a different odorant punished with quinine, the aversive strength of quinine varied with the learning context (de Brito Sanchez et al., 2015). It was stronger when bees were trained in a Y-maze in which they could move freely and express rejection of the punished odorant, but it was milder when bees were harnessed and had to learn the odor discrimination in the absence of movement (olfactory PER conditioning; de Brito Sanchez et al., 2015).

\subsection{Behavioral responses to salts}

Honey bees sense salts, in particular when they collect water, which is an important task for colony temperature regulation (Kühnholz \& Seeley, 1997). Salts are also important as metabolites for the regulation of physiological state (Louw \& Hadley, 1985) and for larval feeding (Nicolson, 2009). Bees, in particular water foragers, are known to prefer compound-rich "dirty" water sources with specific salt concentrations over clean water sources (Bonoan et al., 2017; Butler, 1940).

Low concentrations of salts are generally attractive to bees while high concentrations are aversive, which is consistent with observations in mammals (Chandrashekar et al., 2010; Oka et al., 2013). Von Frisch (1934) showed that increasing the concentration of a $\mathrm{NaCl}$ solution added to sucrose solution diminished progressively the attraction of bees trained to collect pure sucrose solution. In experiments with harnessed bees (Lau \& Nieh, 2016), appetitive PER responses were observed when bees were stimulated with diluted saline solutions $\left(1.5 \%-3 \% \mathrm{NaCl}\right.$ and $\left.1.5 \% \mathrm{MgCl}_{2}\right)$ but such responses decreased with increasing salt concentrations. A similar trend was found for $\mathrm{KCl}$ and $\mathrm{Na}_{2} \mathrm{PO}_{4}$, which were appetitive between $0.4 \%$ and $1.2 \%$ but not at higher concentrations (Lau $\&$ Nieh, 2016). These results account for the use of concentrated $\mathrm{NaCl}$ solution (e.g., $3 \mathrm{M}$ ) as an efficient negative reinforcement in olfactory PER conditioning with harnessed bees. When an odorant is paired with $\mathrm{NaCl}$ solution delivered to the antennae and proboscis, bees learn to inhibit their responses and reject the punished odorant (Aguiar et al., 2018; Bhagavan \& Smith, 1997; de Brito Sanchez et al., 2015; Cook et al., 2005; Getz \& Smith, 1987). 
High sensitivity to different concentrations of saline solutions may be localized in the proboscis and associated appendages rather than at the level of the antennae. In the gustatory conditioning of the SER in which bees learn to differentiate tastants delivered to the antennae based on their association or not with an electric shock (Guiraud et al., 2018, Figure $3 b$ ), they learned to discriminate neither $3-\mathrm{M} \mathrm{NaCl}$ from distilled water nor from $100-\mathrm{mM} \mathrm{NaCl}$ solution, which in turn was not discriminated from $\mathrm{KCl} 100 \mathrm{mM}$ (Guiraud et al., 2018). Therefore, salt detection appears mediocre at the antennal level. On the contrary, a high sensitivity to saline solutions was found at the level of the tarsomeres of the forelegs (de Brito Sanchez et al., 2014; see below).

As for sugars, honey bees exhibit interindividual differences in their sensitivity and preference for salts (Lau \& Nieh, 2016), which may again reflect the existence of different thresholds of responsiveness underlying division of labor within the hive (see above). For instance, bees show variations in their salt preferences, with some individuals preferring lower salt concentrations and others slightly higher concentrations (Lau \& Nieh, 2016). This variability suggests some level of specialization among water foragers (Lau \& Nieh, 2016). This result is interesting in the light of the known specialization of some bees in the task of water collection (Robinson et al., 1984). In addition, foraging for salts is seasonally modulated (Bonoan et al., 2017), which may be due to seasonal variation in colony needs. For instance, $\mathrm{CaCl}_{2}, \mathrm{MgCl}_{2}$, and $\mathrm{KCl}$, which are commonly found in pollen, are preferred in autumn when pollen is scarce but are avoided during summer when pollen is abundant (Bonoan et al., 2017).

\section{5 | Behavioral responses to acids}

Sour taste, the taste sensation evoked by acids, is less well understood than other taste modalities in bees and other insects. Acids are generally toxic to animals and may indicate that food is unripe or spoiled (DeSimone et al., 2001). Von Frisch reported that honey bee foragers trained to collect sucrose solution reject diluted acid solutions. Rejection was similar to that of pure water, which makes conclusions on the taste quality of these acid solutions difficult (von Frisch, 1934). In another set of experiments, von Frisch added different acids to sucrose solution so that the behavioral responses he recorded may have reflected either sensitivity to acids per se or the perception of a sucrose solution modified by the addition of acids (see discussion above on bitter taste; von Frisch, 1934). Von Frisch found that higher concentrations of acids induced a rejection of the sucrose solution in an acid- and concentration-dependent manner. Bees were particularly sensitive to formic acid, tartaric acid, and lactic acid, which induced higher rejection at lower concentrations. They were more tolerant to the addition of succinic acid and acetic acid and exhibited intermediate rejection for citric acid (von Frisch, 1934). For other acids, the concentration dependence effect may lead to a preference for the mixture of sucrose and acid solutions. This was the case in later experiments in which mixtures including caffeic and genistic acids were preferred to a pure sucrose solution (Hagler \& Buchmann, 1993).

As for bitter substances, these results do not allow to conclude on the presence of a dedicated acid sensing channel in the gustatory system of honey bees. Increased rejection of sucrose spiked with different acids may reflect a decrease in appetitive motivation for a solution that has been denatured by the addition of acids rather than a direct rejection of the acids themselves.

\section{3 | TASTANT DETECTION AT THE PERIPHERY - GRNS}

In the honey bee, GRNs are housed within hair-like sensilla chaetica and sensilla basiconica (Esslen \& Kaissling, 1976). Gustatory sensilla chaetica can be found essentially on the antennae, while gustatory chaetica and basiconica are found on the mouthparts and forelegs (de Brito Sanchez et al., 2005, 2014; Whitehead, 1978; Whitehead \& Larsen, 1976a, 1976b). Sensilla basiconica also exist on the antennae, but they mediate olfactory detection (Esslen \& Kaissling, 1976). These sensilla basiconica contain olfactory receptor neurons that project to a specific region of the antennal lobe, the primary olfactory center of the insect brain, which participates in an olfactory subsystem responding to colony odors and pheromone odors (Carcaud et al., 2015; Kropf et al., 2014). As some of these odorants have low volatility, their detection may require direct contact chemoreception, thus establishing a diffuse separation between taste and olfaction. Here we will not further elaborate on this particular case but focus exclusively on electrophysiological responses of pure GRNs, recorded so far from sensilla chaetica.

The highest density of gustatory sensilla chaetica is found on the terminal antennomere, that is, on the tip of the antennae (Esslen \& Kaissling, 1976). Each gustatory sensillum hosts three to five GRNs, each of which projects a dendritic branch to the sensillum apex (Mitchell et al., 1999; Whitehead \& Larsen, 1976a; Figure 1b). The specificity of several GRNs located on different body appendages has been studied by means of single-sensillum recordings (Boeckh, 1962; Boeckh et al., 1965; Kaissling et al., 1989; Kaissling \& Thorson, 1980; Olsson \& Hansson, 2013; Schneider \& Hecker, 1956). This electrophysiological technique consists in obtaining extracellular recordings of GRNs by means of an electrode establishing electrolytic continuity with the receptor hemolymph in which the dendrites of these neurons bathe. Thus, 
stimulating the neurons via the same recording electrode loaded with the tastants to be tested provides information about GRN tuning and sensitivity. Individual GRNs can be distinguished based on their different temporal response patterns and amplitudes of their action potentials, which are mainly due to different dendrite diameters (Hansson et al., 1994; Kaissling \& Colbow, 1987). Several studies have characterized the responses of GRNs located on different body appendages upon stimulation with the abovedescribed tastant categories.

\section{1 | Electrophysiological responses to sugars}

The first recordings of GRNs responding to sugars in the honey bee were obtained from sensilla chaetica located on the galea (Whitehead \& Larsen, 1976a; Figure 4a). GRNs responding to sugars exhibited a higher sensitivity and higher response rates upon stimulation with sucrose followed by glucose and then by fructose. Recordings of sensilla chaetica located on the labial palps showed also maximal responses to sucrose, but in this case, fructose induced higher responses than glucose (Whitehead, 1978). More recently, two GRNs were found in galeal sensilla of bumble bees (Miriyala et al., 2018), which exhibit bursts of spikes in response to stimulation with sucrose. Spike bursting is abolished when sensilla are exposed to the gap- junction blocker carbenoxolone. This suggests that bursting in response to a sugar ligand might arise from inhibitory interactions between GRNs connected by electrical synapses. The consequence of this lateral inhibition between GRNs would be a high resistance to sensory adaptation upon sucrose stimulation. A similar pattern of activity was observed in galeal sensilla of honey bees (Miriyala et al., 2018) so that the same mechanism was proposed for this insect.

Antennal GRNs were also recorded (de Brito Sanchez et al., 2005; Haupt, 2004) as the last antennal segment exhibits a high density of gustatory sensilla (Esslen \& Kaissling, 1976). GRNs within these sensilla respond to sucrose concentrations down to at least $0.1 \%$. A high degree of variability in the response of antennal sensilla to the same sucrose concentration was found, which was interpreted as a way to extend the dynamic range of sucrose perception over a large range of concentrations (Haupt, 2004). Responses to sucrose were inhibited by the addition of very low concentrations of bitter substances (e.g., 0.01-mM quinine added to 15 -mM sucrose solution; see below), thus showing the suppressive effect of these substances on sugar receptor neurons (de Brito Sanchez et al., 2005; Figure 4b).

Tarsal GRNs responding to sugars were also recorded in sensilla chaetica located on the tarsomeres (third and fourth tarsomeres) and on the claws of the posterior pair of legs (de Brito Sanchez et al., 2014). Tarsomere sensilla responded to sucrose solution, but responses were rather due to the contact with the electrolyte $(\mathrm{KCl})$ contained in the stimulating solution as these sensilla are particularly sensitive to salts (see below). These sensilla did not show a dose-response relationship when stimulated with different sucrose concentrations, thus suggesting that they do not host a sucrose receptor cell. On the contrary, claw sensilla exhibited high responsiveness to sucrose, indicating that the claws are essential for sensing sucrose via the forelegs (de Brito Sanchez et al., 2014).

\section{2 | Electrophysiological responses to amino acids}

From the five neurons hosted within galeal sensilla, one is a mechanoreceptive neuron, which ends at the base of the sensilla and senses deflections experienced by the cuticular hair upon contact with an object's surface. A second neuron responds to sugars and a third (and possibly a fourth) neuron responds to electrolytes (Whitehead \& Larsen, 1976a). It was suggested that the fifth neuron could be responsive to amino acids, among other tastants (Whitehead \& Larsen, 1976a). So far, only one study observed responses to amino acids delivered to the galea (Lim et al., 2019). Single-sensillum recordings from the 10 most distally located sensilla were performed upon stimulation with various concentrations of L-glutamate and L-aspartate (50, 100, and $200 \mathrm{mM}$ ), which are major components of pollen (Szczęsna, 2006). Responses increased linearly with the solute concentration of both amino acids (Figure 4c), thus showing the presence of a GRNs tuned to these tastants (Lim et al., 2019).

\section{3 | Electrophysiological responses to bitter substances}

Stimulation of sensilla chaetica located on the antennae with different concentrations of bitter substances such as quinine and salicin did not induce any action potential, consistently with an absence of sensitivity to these substances (de Brito Sanchez et al., 2005). A similar result was found when GRNs located on the tarsi were stimulated with bitter substances (de Brito Sanchez et al., 2014). Yet recordings of the galeal sensilla chaetica stimulated with quinine or amygdalin showed a delayed, specific pattern of action potentials (Wright et al., 2010). Thus, if bees can sense bitter substance per se, they might do so via these specific sensilla. Yet this would have the disadvantage of a "delayed" detection, and it would seem more adaptive for bees to react earlier to aversive, noxious substances (i.e., upon antennal or tarsal contact) before they reach the mouthpieces. 
(a)

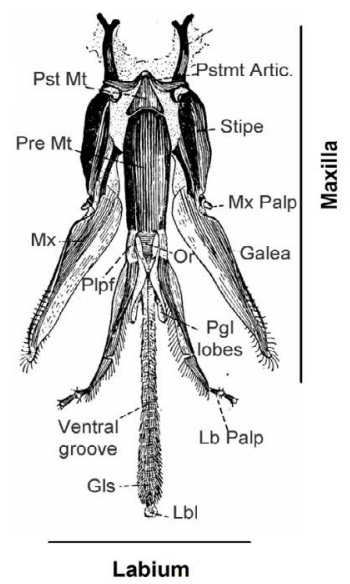

(b)

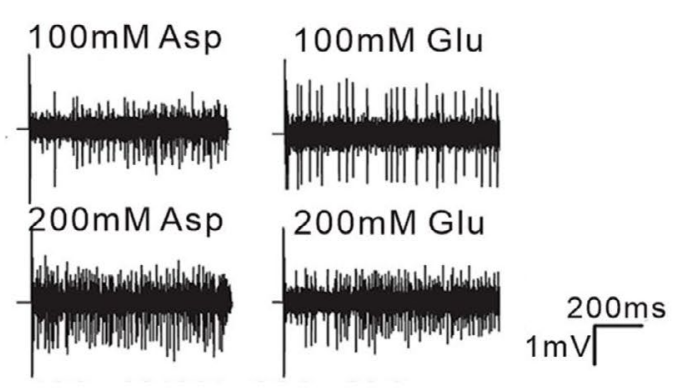

(c)

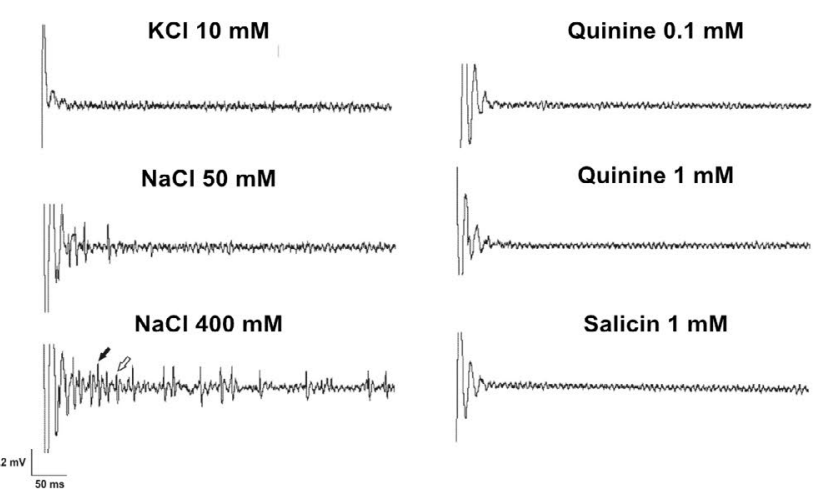

(d)

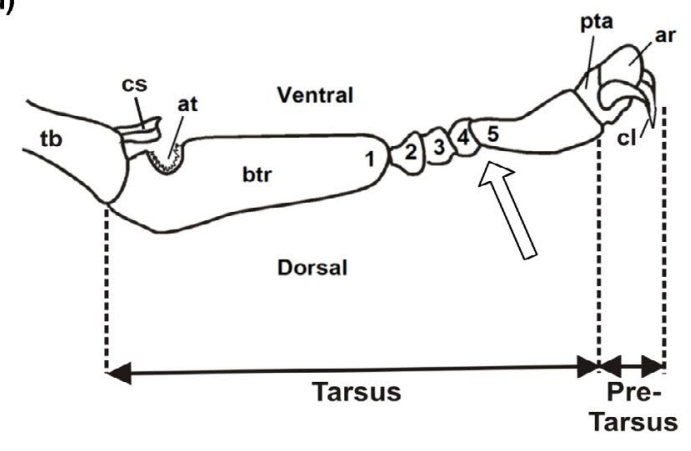

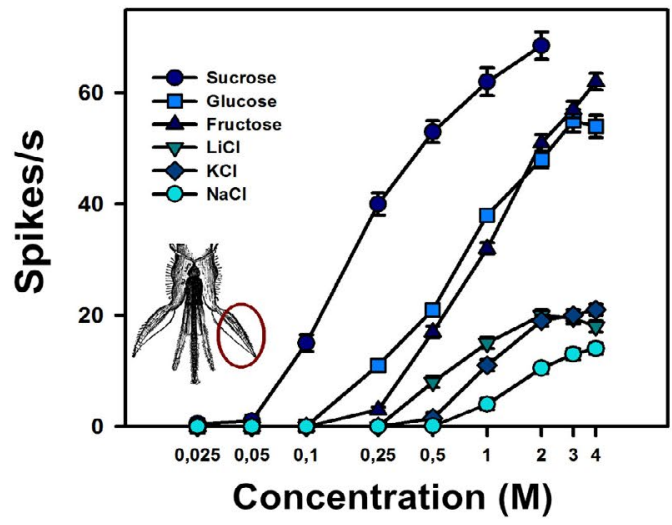
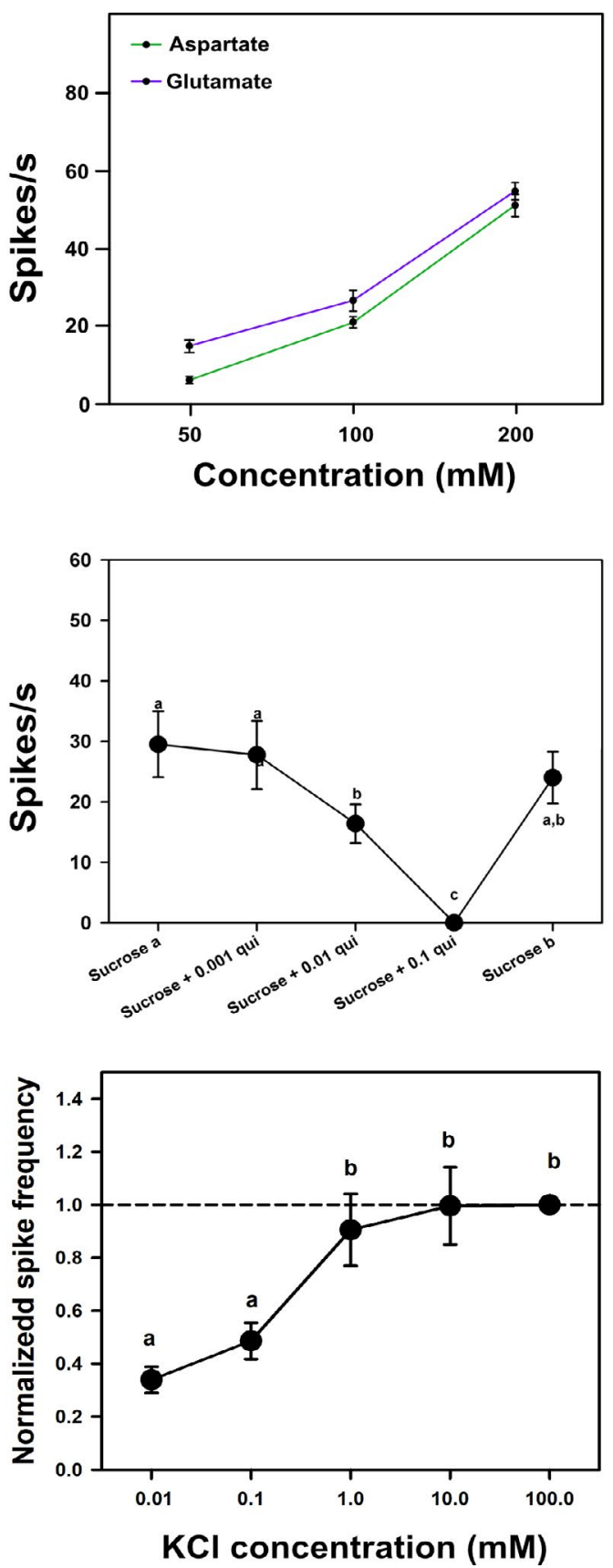
F I G U R E 4 Electrophysiological characterization of gustatory receptor neurons of the honey bee. (a) Left: The mouth pieces of the honey bee. Ventral view of the parts forming the proboscis, with the labium in the middle and the maxillae on the sides, flattened out (adapted from Snordgrass, 1956). Abbreviations: Gls, glossa; Lbl, labellum; Lb Palp, labial palp; Mx, maxilla; Or, salivarium opening; Pgl lobes, paraglossal lobes; Plpf, palpiger; Pre Mt, prementum; Pst Mt, postmentum; Pstmt Artic, postmental articulation. Right: Electrophysiological responses of chaetic sensilla on the galea. Single-sensillum recordings show that neurons within these sensilla respond linearly to the solute concentrations of sucrose, glucose, fructose, $\mathrm{NaCl}, \mathrm{KCl}$, and $\mathrm{LiCl}$ when these are expressed in a logarithmic scale. Each dot represents the mean response $( \pm 2$ SEM) from an average of eight sensilla per 10 bees with two applications per sensillum (i.e., 160 responses recorded). The inset shows the proboscis, with a circle around the galea where these recordings were made (from Whitehead \& Larsen, 1976b). (b) Electrophysiological responses of chaetic sensilla of the galea to amino acids. Left: Examples of recordings obtained upon stimulation with two concentrations of L-glutamate (Glu) and L-aspartate (Asp). Right: Responses to the solute concentrations of Glu and Asp increase significantly and linearly in these sensilla. Dots represent the mean response ( \pm SEM) from an average of five sensilla per seven bees (i.e., 35 responses recorded). From Lim et al. (2019). (c) Electrophysiological responses of antennal chaetic sensilla to salt or bitter tastes. Left: Examples of recordings obtained upon stimulation with different stimulating solutions. $\mathrm{KCl} 10 \mathrm{mM}$; $\mathrm{NaCl} 50 \mathrm{mM}$; $\mathrm{NaCl} 400 \mathrm{mM}$; quinine $0.1 \mathrm{mM}$; quinine $1 \mathrm{mM}$; salicin $1 \mathrm{mM}$. Black and white arrows in (c) show different spike amplitudes. Right: Concentration threshold of quinine necessary to inhibit the response of sucrose receptor cells of the antenna to $15-\mathrm{mM}$ sucrose (i.e., quinine concentration at which complete inhibition of sucrose receptor cells is reached). Sucrose-responding sensilla ( $n=8$ of 3 bees) were stimulated with $15-\mathrm{mM}$ sucrose solution at the beginning (sucrose a) and at the end of the experiment (sucrose b) and with mixtures of sucrose solution $15 \mathrm{mM}$ and quinine at three different increasing concentrations, 0.001, 0.01, and 0.1 mM. The quinine concentration threshold for inhibition of sucrose receptor cells lies between 0.01 and $0.1 \mathrm{mM}$. The abscissa displays the consecutive stimulations and the ordinate, the spike count. Error bars represent SEM. Different letters indicate significant differences between responses depending on quinine concentration. From de Brito Sanchez et al. (2005). (d) Electrophysiological KCl responses of chaetic sensilla located on the tarsi of the honey bee. Left: Scheme of the distal segments of a honey bee foreleg showing the tarsus and the pretarsus. The tarsus has five tarsomeres: a basitarsus (btr: 1), which is the largest tarsomere, and four smaller tarsomeres (2-5). The basitarsus presents a notch of antenna cleaner (at) and the tibia (tb) a closing spine (cs). The distally situated pretarsus (pta) bears a pair of lateral bifid claws (cl) and an arolium (ar), a small pad used to increase adhesion. Right: Normalized mean electrophysiological responses (to $\mathrm{KCl} 100 \mathrm{mM} \pm \pm$ SEM) of chaetic sensilla located on the small tarsomeres (six sensilla from five bees) stimulated with different concentrations of $\mathrm{KCl}(\mathrm{mM})$. These sensilla exhibit a high sensitivity to saline solutions. From de Brito Sanchez (2011)

In sensilla chaetica located on the antennae (de Brito Sanchez et al., 2005), galea (Wright et al., 2010), and tarsi (de Brito Sanchez et al., 2014), electrophysiological responses to sucrose were inhibited by the addition of quinine, consistently with the hypothesis that rejection of sucrose solutions containing quinine involves sucrose receptor inhibition (see Figure $4 \mathrm{~b}$ and above). This inhibitory effect was also observed in adult blowflies (Protophormia terraenovae), fruit flies D. melanogaster, and moths (Heliothis virescens) stimulated with a mixture of sucrose and quinine, both at the behavioral and electrophysiological levels (French et al., 2015; Jørgensen et al., 2007; Liscia \& Solari, 2000; Meunier et al., 2003).

The mechanism underlying sugar-sensing inhibition by bitter molecules such as quinine remains unknown. As "bitter" substances exhibit considerable variation in their chemical structures, a variety of modes of action may exist (French et al., 2015). Bitter molecules may interfere with the detection of sugar molecules at sugar receptors, as shown for Drosophila (Sellier et al., 2011), or they may block or interfere with transduction processes in sugar receptor neurons. In addition, some bitter molecules may suppress the activity of these neurons because of their toxicity (Tanimura \& Shimada, 1981).

In antennal sensilla of honey bees, inhibition of neural activity was specific for quinine, as salicin, another bitter substance, did not inhibit cellular responses to sucrose. This difference may reflect differences in the structure of bitter substances (quinine is an alkaloid while salicin is a glucoside). Inhibition was reversible because stimulating with 15-mM sucrose solution after stimulating with a mixture of the same sucrose solution, and $0.1-\mathrm{mM}$ quinine yielded a cellular response similar to that obtained for $15-\mathrm{mM}$ sucrose solution alone before mixture stimulation (de Brito Sanchez et al., 2005). This reversibility indicates that quinine does not damage the sucrose GRNs.

\subsection{Electrophysiological responses to salts}

Electrophysiological responses to saline solutions (e.g., $\mathrm{NaCl}, \mathrm{KCl}, \mathrm{LiCl}, \mathrm{MgCl}_{2}, \mathrm{CaCl}_{2}$ ) have been recorded in various studies (de Brito Sanchez et al., 2005, 2014; Whitehead, 1978; Whitehead \& Larsen, 1976a, 1976b) focusing on sensilla located on various gustatory appendages of the honey bee (e.g., palps, galea, and tarsi). In all cases, the presence of receptor cells responding to salts (in particular to $\mathrm{NaCl}, \mathrm{KCl}$ and $\mathrm{LiCl}$ ) was reported (see Figure 4a for galeal sensilla). Sensitivity to saline solutions was found in GRNs hosted by sensilla chaetica of the antennae (de Brito Sanchez et al., 2005), mouth parts (Whitehead, 1978; Whitehead \& Larsen, 1976a; 1976b), and tarsi (de Brito Sanchez et al., 2014). Sensitivity to saline solutions was particularly enhanced in GRNs located on the third and fourth tarsomeres. Their spike frequency increased significantly with $\mathrm{KCl}$ concentration, especially 
in the range of low concentrations $(0.01,0.1$, and $1 \mathrm{mM})$, including concentrations that are normally undetectable by GRNs responding to salts in other body appendages (de Brito Sanchez et al., 2014). For instance, responses of tarsal GRNs were recorded at a $0.01-\mathrm{mM} \mathrm{KCl}$ concentration, which is normally used as contact electrolyte in electrophysiological recordings, while $10-\mathrm{mM} \mathrm{KCl}$ was needed to induce a response from antennal GRNs (de Brito Sanchez et al., 2005). This difference could be adaptive, as hovering bees in search of saline solutions available in water ponds would rather first contact water with their tarsi to assess salts content (de Brito Sanchez et al., 2014).

\section{| 3.5 Electrophysiological responses to acids}

Data on honey bees'" electrophysiological responses to acids are lacking. The sensitivity of free-flying honey bees to certain acids added to sucrose solution shown in the behavioral experiments of von Frisch (1934, see above) could be due to the presence of an acid-tuned GRN or could reflect the effect of acids (e.g., inhibition) on the response of other specialized GRNs (e.g., sweet GRNs). Interestingly, von Frisch proposed a receptor-based theory to explain the variable rejection of sucrose solutions spiked with different acids. He argued that the degree of dissociation of an acid, which allows distinguishing between strong acids that dissociate completely to form ions in solution, and weak acids that ionize only partially and reversibly, is a key feature accounting for the bees' response. According to this dissociation theory, weak acids would be perceived as being more acid because only a small fraction would be dissociated in the hemolymph, leaving a large putative proton pool available in the non-dissociated form. If the acid reaches the GRN surface, more protons could be made available at the activation site, which would result in a higher perceived acidity (von Frisch, 1934, p. 112).

Eighty-three years later, the same idea was proposed to account for $\mathrm{Ca}^{2+}$ responses to acids of GRNs in the tarsi of $D$. melanogaster (Chen \& Amrein, 2017), yet without mentioning von Frisch's original proposal. These GRNs are dedicated to sour taste and are more activated by weak than by strong acids. Coincidently with von Frisch's dissociation hypothesis, Chen and Amrein (2017) proposed that activation of these sour neurons might be mediated by proton translocation as protons were shown to be necessary and sufficient for activating these neurons, whereas the presence of the conjugate carboxylic base was not. They suggested that in the case of strong acids, translocation of free protons would induce activation of the neurons, but not all protons in the hemolymph may reach the pore channel of the receptor on the GRN surface. In the case of weak acids, only a small fraction would be dissociated in the hemolymph, leaving a large putative proton pool available in the non-dissociated form to reach the pore channel and activate the receptor site (Chen \& Amrein, 2017).

\section{4 | THE MOLECULAR BASIS OF PERIPHERAL TASTANT DETECTION}

The sequencing of the honey bee genome (2006) was a critical step allowing to investigate the molecular basis of gustatory perception of this insect. Yet data on expression patterns of different GR types in different organs are still scarce or missing so that in many cases, conclusions on bee GR types are based on Drosophila homologs and their known functions.

Firstly, 10 GRs genes (AmGr) and 3 AmGrs pseudogenes (i.e., which do not code for functional proteins) were identified, thus indicating the presence of 10 functional GRs (Robertson \& Wanner, 2006). Later, the sequencing of bumble bee genomes (Bombus terrestris and Bombus impatiens) led to a revision of the honey bee genome, and the number of GR genes and of functional GRs was extended to 11 and the number of pseudogenes to 4 (Sadd et al., 2015).

These numbers are low compared to those of other insects. For instance, the fruit fly D. melanogaster possesses 68 functional GRs encoded by 60 Grs (Dunipace et al., 2001; Robertson et al., 2003; Scott et al., 2001), the mosquito Anopheles gambiae 76 functional GRs encoded by 52 Grs (Hill et al., 2002), and the Argentine ant (Linepithema humile) 96 functional GRs encoded by 116 Grs (Smith et al., 2011). The reduced number of Grs found in the honey bee has been interpreted as the result of a feeding specialization on floral products (Robertson \& Wanner, 2006), which would be associated with a reduction in tastant diversity. This interpretation has been questioned as a similar reduction in the number of Grs has been found in other Hymenoptera with different, omnivorous feeding regimes (e.g., $11 \mathrm{Grs}$ and $6 \mathrm{Grs}$ in the carpenter ant Camponotus floridanus and the jumping ant Harpegnathos saltator, respectively; Bonasio et al., 2010). Moreover, ecological analyses indicate that the gustatory world of bees does not seem as limited as it was long thought to be.

Besides GRs, the sequencing of the honey bee genome also revealed the presence of IRs. Twenty-one IR genes have been reported for the honey bee (Sadd et al., 2015), which is less than the 66 IR genes and the 9 putative pseudogenes of D. melanogaster (Benton et al., 2009; Croset et al., 2010). So far, no study has addressed a possible role of honey bee IRs in gustation or the possible interaction between IRs and GRs as a condition for detecting some tastants, as is the case in Drosophila (Jaeger et al., 2018). If such interactions exist in bees, they may greatly extend the number of functional combinations for detecting and discriminating tastants. 
The same lack of knowledge applies to TRPA-based taste detection. Honey bees do not express the TRPA1 channel but a hymenoptera-specific channel, AmHsTRPA (Matsuura et al., 2009), which is involved in heat perception (Junca \& Sandoz, 2015; Kohno et al., 2010). This is consistent with the fact that TRPA1 in D. melanogaster and A. gambiae is activated by changes in temperature (Kang et al., 2012; Kwon et al., 2008; Viswanath et al., 2003; Wang et al., 2009; Zhong et al., 2012). Whether AmHsTRPA also contributes to sense aversive chemical substances remains to be determined.

Three members of the pickpocket (Ppk) gene family (DEG/ENaC channels) are present in the honey bee genome: Ppk28, Ppk19, and a sodium channel protein Nach (The Honeybee Genome Sequencing Consortium, 2006). Their possible role in gustation has not been studied. Yet the Ppk28 found in the honey bee genome is not homolog of a Ppk expressed in the fruit fly genome as their structures are different (2,448 pb for the Drosophila Ppk28 and 5,968 pb for the honey bee Ppk28), thus asking for caution when elaborating on its possible function.

\section{5 | EVOLUTION OF THE GR MULTIGENIC FAMILY}

The sequencing of the honey bee genome allowed to identify the presence of GRs and IRs and enables, in addition, to use comparative analyses between species to address the evolution of taste mechanisms and search for orthologs guiding functional analyses of receptor function. To investigate the evolution of the GR multigenic family, we gathered all known 359 proteins of the GR family reported for 6 insect species, including 15 proteins for the honey bee, A. mellifera (AmGr); 25 proteins for the bumble bee, $B$. terrestris $(\mathrm{BtGr}) ; 76$ proteins for the Malaria mosquito, A. gambiae (AgGr); 68 proteins for the fruit fly $D$. melanogaster $(\mathrm{DmGr}) ; 117$ proteins for the Argentinean ant, L. humile (LhGr); and 58 proteins for the parasitoid wasp, Nasonia vitripennis (NvGr; Robertson \& Wanner, 2006; Sadd et al., 2015; Smith et al., 2011). Some proteins are not functional and were labeled as pseudogenes (PSE) in our reconstruction. Multiple sequence alignments were carried out with ClustalW under default parameters (Thompson et al., 1994), resulting in a matrix of 359 terminals with 528 aligned amino acids. A Maximum Likelihood gene tree was reconstructed using a CAT model with RaxML v8.2.12 (Si Quang et al., 2008; Stamatakis, 2014); node support was estimated from 1,000 bootstraps. The RaxML reconstruction was performed on the CIPRES Science Gateway online server (Miller et al., 2010). In the absence of outgroups, the tree was rooted on the sugar receptor candidates to mirror the topology of Sadd et al. (2015).

Our phylogenetic reconstruction (Figure S1) yielded 121 out of 357 nodes exhibiting support values equal to or higher than 70. We identified nine sets of GR orthologs for Hymenoptera that are highly supported (bootstrap support value higher than 95\%; or BS > 95). The Gr1, Gr2, Gr3, and Gr6 proteins are orthologs for all four hymenopteran species (honey bees, bumble bees, Argentine ants, and Nasonia wasps). The Gr4, Gr7, and Gr11 proteins are also orthologs but only for honey bees, bumble bees, and Argentine ants, suggesting that they might be specific to Aculeata or that an orthologue loss occurred in N. vitripennis. Finally, the Gr8, Gr9, and Gr12 are orthologs only for the Apidae (honey bees and bumble bees). This differentiation of Grs (at least for Gr4, Gr7-10, and 12) in Hymenoptera reveals specific Gr evolution within this group so that drawing straightforward conclusions on possible orthology between characterized DmGrs and unidentified AmGrs could lead to erroneous interpretations and should be avoided. For instance, our analysis highlights that no evident orthology relationships exist between DmGrs for bitter-taste detection and AmGrs despite previous suggestions in that sense (Simcock et al., 2017). This shows that the absence of bitter-sensing Grs may be Hymenoptera-specific (Figure S1). Interestingly, no Gr strictly tuned to amino acids has been identified in fruit flies until now whereas AmGr10 responds specifically to these tastants (see below). This suggests that this receptor is hymenoptera-specific (Figure 5c).

Although most species express a single protein in these orthologs, we identified six cases of duplication events. In the Argentinean ant L. humile, Grl was duplicated two times (LhGr1.1, LhGr1.2PJ, LhGrl.3PJ) and Gr2 a single time (LhGr2.1PSE, LhGr2.2); in B. terrestris, we identified four duplication events of $G r 8$ (BtGr8, BtGrl4FIX, BtGr16, BtGr18, BtGr20), of Gr9 (BtGr9FIX, BtGr15INT, BtGr17PSE, BtGr19, BtGr21) and of Gr12 (BtGr12, BtGr22, $B t G r 23, B t G r 24, B t G r 25)$. In A. mellifera, only Gr4 was duplicated (AmGr4, AmGr5).

We detected four other important expansions by duplication in the Hymenopteran species considered. Most of the $L$. humile proteins result from a single intense expansion, with a highly supported clade that encompasses 94 out of 117 proteins (BS =97). In $N$. vitripennis, 33 out of 58 proteins form a poorly supported clade that is strongly related to the Gr4 ortholog ( $\mathrm{BS}=54$; and $\mathrm{BS}=99$, respectively), while 8 proteins form another clade that is strongly supported and related to the $\mathrm{Gr} 7$ ortholog ( $\mathrm{BS}=99$ and $\mathrm{BS}=100$, respectively). Finally, 3 out of 15 proteins form a supported clade in A. mellifera (AmGrX, AmGrY, AmGrZ; BS = 100).

Although caution is needed when making functional conclusions on AmGRs based on GRs of D. melanogaster, matching orthologs between AmGrs and DmGrs proved to be useful in some cases and improved our understanding of the bees' gustatory sense. Using this approach, the AmGr1 and AmGr2 proteins were found to be most closely related to the DmGr5a and DmGr64f proteins (Figure 5b), which are sugar receptors among eight DmGr candidate sugar receptors 


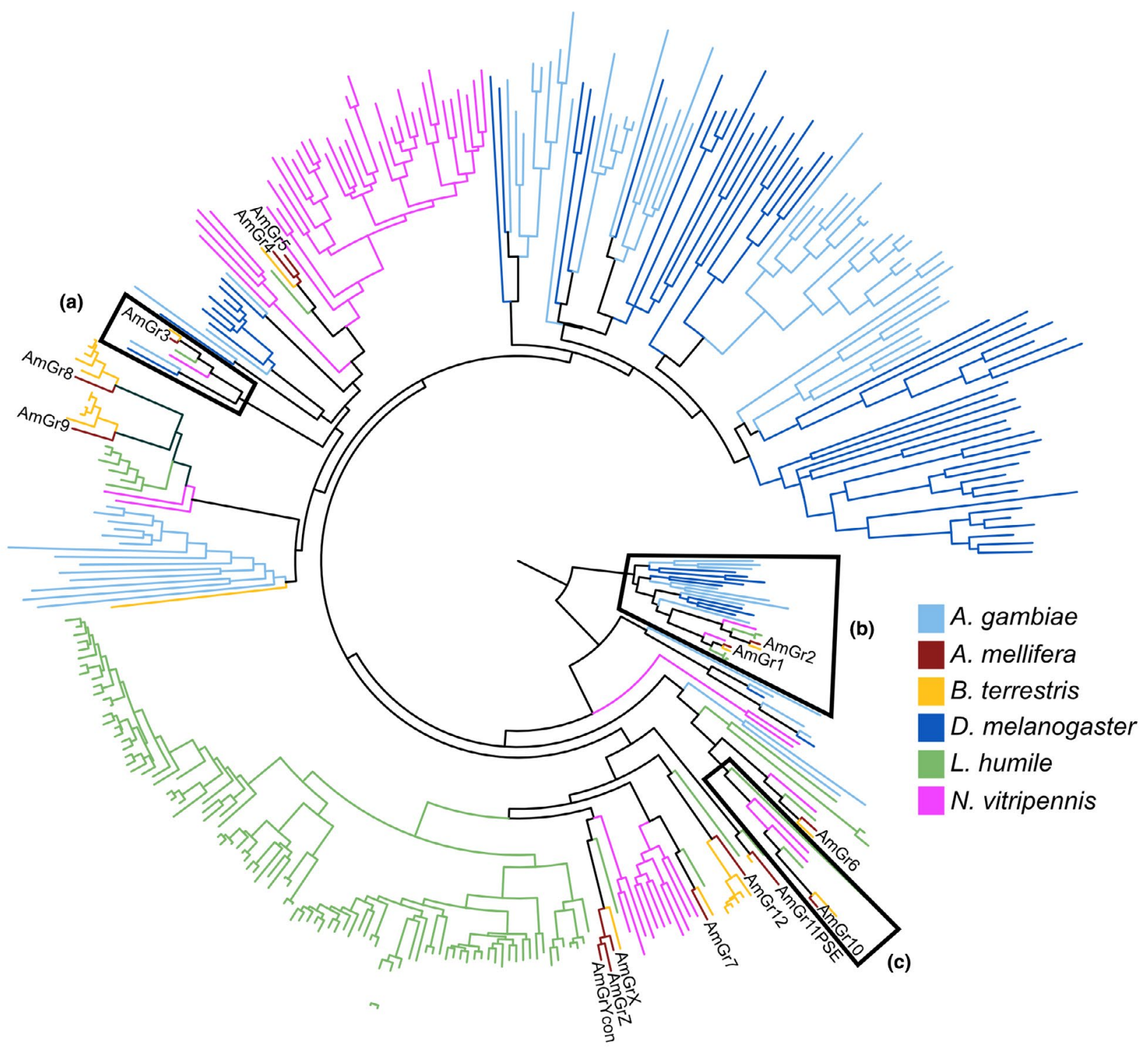

(a) Candidate fructose receptors

(b) Candidate sugar receptors
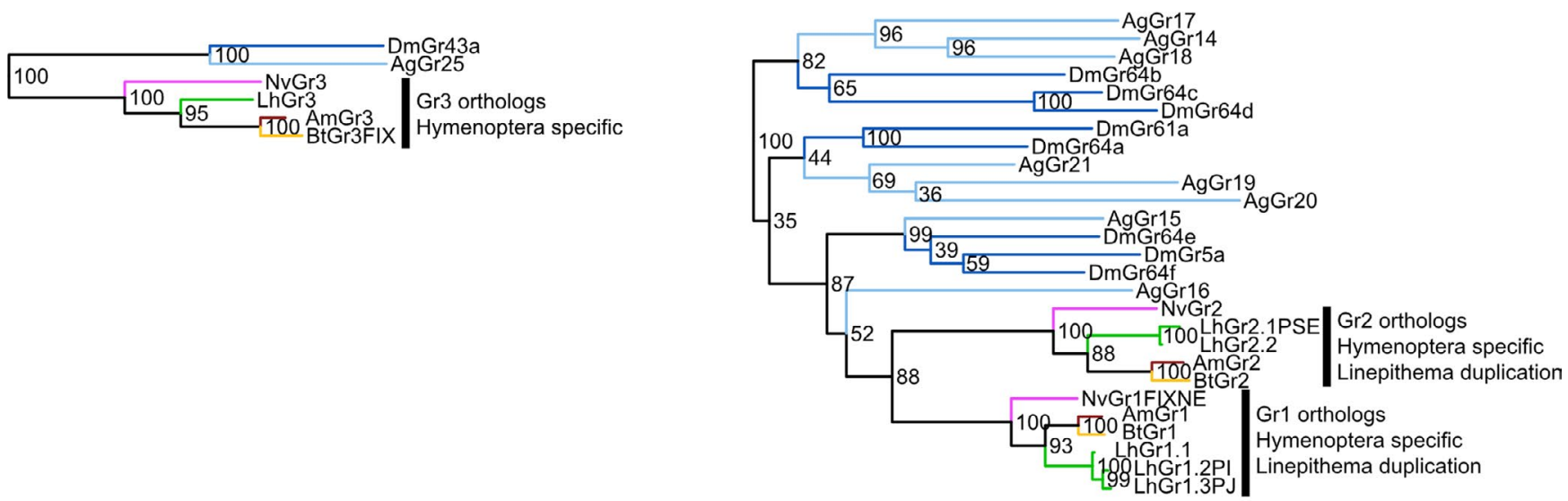

(c) Candidate amino acid receptors

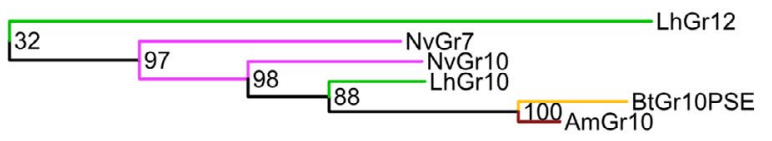

Gr10 orthologs

Hymenoptera specific

Amino acid receptor and division of labor in Apis 
F I G URE 5 Maximum likelihood reconstruction of the gustatory receptor gene family, with an emphasis on (a) candidate fructose receptors, (b) candidate sugar receptors, and (c) candidate amino acid receptors. The reconstruction was performed with a CAT model, using RaxML V8.2.12 on the CIPRES Science Gateway online server (Miller et al., 2010). Node support values were estimated from 1,000 bootstraps. In the absence of outgroups, the tree was rooted on the sugar receptor candidates to mirror the topology of Sadd et al. (2015). Protein sequences included in the reconstruction account for all known genes of four species of Hymenoptera (Apis mellifera, Bombus terrestris, Linepithema humile, and Nasonia vitripennis) and two species of Diptera (Anopheles gambiae and Drosophila melanogaster). Proteins and branches leading to them have been colored for each species to emphasize gene lineages, in red for A. mellifera (Am), orange for B. terrestris (Bt), green for $L$. humile (Lh), pink for $N$. vitripennis $(\mathrm{Nv})$, light blue for A. gambiae (Ag), and dark blue for D. melanogaster $(\mathrm{Dm})$. The complete phylogenetic tree is available in Figure $\mathrm{S} 1$

(Robertson \& Wanner, 2006; Robertson et al., 2003; Scott et al., 2001, our work). Using the same approach, the AmGr3 protein was found to form a highly supported clade including the DmGr43a protein $(\mathrm{BS}=100)$, indicating that they might all act as fructose receptors (Miyamoto et al., 2012; Robertson \& Wanner, 2006), a hypothesis supported by recent experimental evidence (see below). Caution is nevertheless required when hypothesizing functions from orthologs because the effects of mutation, selection, and drift could alter a function or even lead to pseudogenization (Magadum et al., 2013). In addition, the possibility of elaborating such a comparative analysis was restricted to 3 out of 11 identified AmGrs (AmGr1, AmGr2, AmGr3), while 8 AmGrs could not be directly related to any $D m G r$ gene.

Sadd et al. (2015) suggested that the AmGr4/5 lineage, which was thought to be an ortholog of $D m G r 28 a / b$ (Robertson \& Wanner, 2006), may be a specific duplication in Apis as there is only one ortholog gene in B. terrestris (BtGr4PSE), which is a pseudogene that may have lost its function in bumble bees and cannot therefore duplicate. AmGr6 to AmGr9 have no apparent orthology to any of the Grs of the fruit fly Robertson and Wanner (2006), which may indicate that the GRs encoded by these genes potentially represent a Hymenoptera-specific lineage with unique functions (Sadd et al., 2015). The phylogenetic analyses of Sadd et al. (2015) suggest that AmGr8, AmGr9, and AmGrl2 belong each to one of the three set of duplicated genes in $B$. terrestris, meaning that their unknown functions could be related. In addition, $A m G r 6, A m G r 7$, and $A m G r 10$ are orthologs of $B t G r 6, B t G r 7$, and $B t G r 10$, respectively. AmGr6 is also an ortholog of LhGr6 (Smith et al., 2011; Figure S1).

According to Robertson and Wanner (2006), the honey bee genome contains $\sim 50-\mathrm{Gr}$ pseudogenes. Only three of these pseudogenes, $A m G r X, Y$, and $Z$, were built in fulllength versions. AmGrll is thought to be a pseudogene like AmGr $X, Y$, and $Z$ but it is an ortholog of BtGrll and LhGrll (Sadd et al., 2015; Smith et al., 2011; Figure S1) which are functional genes. Although this suggests a loss of function in the case of AmGrll, the effect of such loss on honey bee's taste is unknown as the specificities of BtGrll and LhGrll are also unknown.

Coupling molecular approaches with functional neurophysiology provides a valuable strategy to overcome the deficits in genetic-tool availability in the honey bee. For instance, expressing GRs in Xenopus oocytes and coupling this expression with electrophysiological recordings (e.g., patch clamp recordings) enable the characterization of AmGr tuning (Değirmenci et al., 2018; Jung et al., 2015; Lim et al., 2019; Takada et al., 2018). Alternatively, the development of RNAi or CRISPR/Cas9 methods allows knocking out a GR gene and determining the consequences of its loss via electrophysiological and/or behavioral analyses (Değirmenci et al., 2020).

\section{6 | THE MOLECULAR-RECEPTOR BASIS FOR TASTANT DETECTION}

\section{1 | Detection of sugars-AmGr1 and AmGr2}

From the 11 functional GR genes identified in the bee genome, $A m G r 1$ and $A m G r 2$ are orthologs of eight candidate sugar receptor genes in D. melanogaster (Robertson \& Wanner, 2006). Both are co-localized in antennal GRNs located within sensilla chaetica (Jung et al., 2015). AmGrl is highly expressed in the distal segment of the antenna, consistently with the highest density of sensilla chaetica found there (Esslen \& Kaissling, 1976). When expressed in a Xenopus oocyte, $\mathrm{AmGrl}$ - which is closely related to the fruit fly sugar receptors DmGr64a and DmGr5a (Figure 5)—responds to sucrose, glucose, maltose, and trehalose in a dose-dependent manner but not to fructose. AmGr2 does not respond to any of these sugars (Jung et al., 2015). However, a higher sensitivity to glucose and a lower sensitivity to sucrose, maltose and trehalose is observed when AmGrl and AmGr2 are coexpressed in Xenopus oocytes compared with the sole expression of AmGrl (Jung et al., 2015). In addition, co-expression of $A m G r 1$ and $A m G r 2$ results in more stable responses of GRNs when compared to the responses of GRNs expressing only AmGrl (Jung et al., 2015).

These findings suggest that the sugar receptors AmGr1 and AmGr2 can form heterodimers, monomers, or mono-dimers and that AmGr2 may act as a co-receptor for AmGr1 conferring a wider detection range for sugars (Jung et al., 2015). Thus, AmGr1 may exhibit different ligand properties depending on the co-expression with $A m G r 2$ in the same gustatory neuron. In that sense, the role of $A m G r 2$ would be similar to 
that of some Grs of D. melanogaster such as DmGr64f and DmGr93a (Jiao et al., 2008; Lee et al., 2009), which increase both the sensitivity and the range of detectable nutrients (Fujii et al., 2015; Miyamoto et al., 2013; Slone et al., 2007; Wisotsky et al., 2011) and stabilize GRN responses. A similar role has been found for olfactory co-receptor genes in the fruit fly olfactory system (Benton et al., 2006; Larsson et al., 2004).

\section{2 | Detection of sugars-AmGr3}

Interestingly, GRNs expressing AmGrl do not respond to fructose (Jung et al., 2015) although various behavioral experiments showed that honey bees distinguish this sugar from sucrose (Ayestaran et al., 2010; von Frisch, 1967). These findings suggested that fructose binds to another GR, possibly to that encoded by AmGr3 (Robertson \& Wanner, 2006). AmGr3 is an ortholog of fructose receptor genes found in other insect species as suggested by our phylogenetic analysis (Figure 5a). Neurons expressing $D m G r 43 a$ in the protocerebrum allow sensing fructose in the hemolymph, promote food intake in hungry flies, and suppress food intake in fed flies (Miyamoto \& Amrein, 2014; Miyamoto et al., 2012). These results indicate that $\mathrm{DmGr} 43 \mathrm{a}$ might act as a nutrient sensor. In the silk moth, $B m G r 9$ may have a similar role as the receptor it encodes specifically binds to fructose and is expressed in the larval gut (Sato et al., 2011). Recent studies in which AmGr3 was transiently expressed in Xenopus oocytes have shown that in honey bees AmGr3 is specialized in fructose detection (Değirmenci et al., 2020; Takada et al., 2018). When double nonsense mutations were introduced into
AmGr3 using a CRISPR/Cas9 approach, the mutants exhibited a very low fructose responsiveness compared to control bees but responded normally to sucrose (Değirmenci et al., 2020; Figure 6a,b). Some mutant bees still responded to fructose in these experiments, thus leading to the suggestion that perception of fructose could occur, though in a reduced manner, via $A m G r 1$ and its co-receptor $A m G r 2$, when co-expressed in the same gustatory neuron.

Analyses of AmGr3 expression in tissues of adult bees revealed higher expression levels in the gut of foragers and in the antennae and legs of nurses (Takada et al., 2018). Further studies demonstrated $A m G r 3$ expression in the bee brain and showed high expression in starved bees and, conversely, lower levels in bees fed on a diet of fructose (Simcock et al., 2017). These results support the hypothesis that $A m G r 3$ acts as an internal sensor and regulator of sugar homeostasis and thus as a key element for sugar intake in the honey bee.

To sum up, from the 11 functional GR genes identified in the honey bee, three participate in different aspects of sugar sensing. While AmGrl confers sensitivity to various sugars, including sucrose, glucose, trehalose, and maltose, $A m G r 2$ seems to act as a co-receptor of $A m G r l$, increasing its sensitivity and the range of sugars detected. AmGr3 is dedicated to fructose detection and besides its peripheral role, its brain and gut expression are consistent with an additional role as an internal nutrient sensor. Importantly, these receptor genes are not only expressed in peripheral taste organs (antennae, mouthparts, tarsi, etc.) and in the gut but also on the entire surface of the body and in the brain, where they may not act as conventional sugar receptors but may participate in signaling pathways of nutrient sensing.
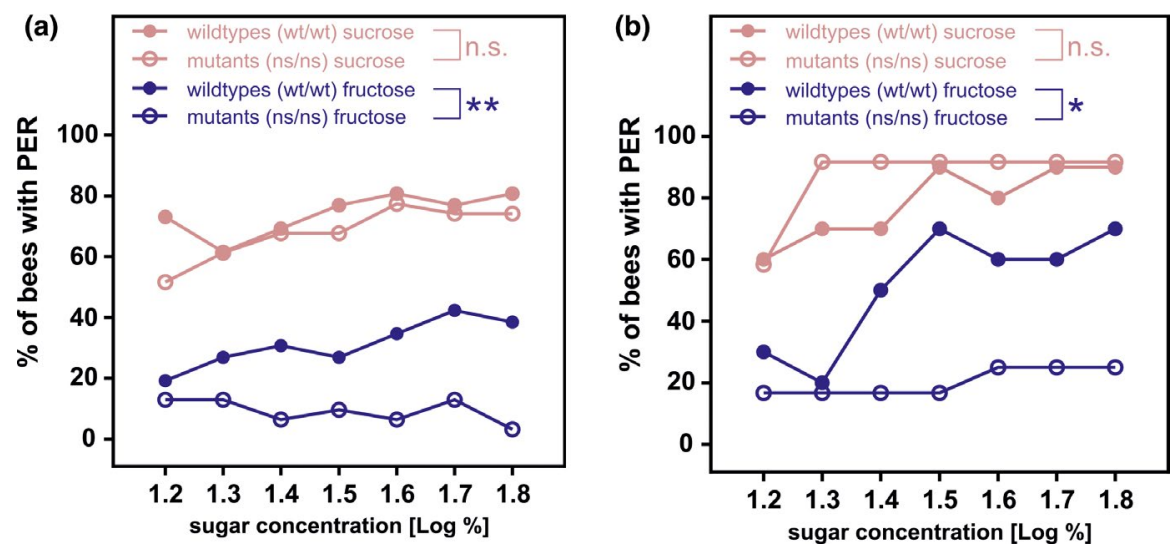

F I G U RE 6 Molecular analyses of GRs in honey bees. Nonsense mutation introduced by CRISPR/Cas9 to AmGr3 induced changes in behavioral sucrose responsiveness. The graph shows the percentage of bees responding to increasing sugar concentrations (16\%, 20\%, $25 \%, 32 \%$, $40 \%, 50 \%$, and $63 \%$, corresponding to a $\log$ of $1.2,1.3,1.4,1.5,1.6,1.7$, and 1.8, respectively). Responses were recorded upon stimulation with either fructose (blue) or sucrose (red). Panels (a) and (b) show two replicates of the same experiment. In both cases, AmGr3 mutants (ns/nsdouble mutants) displayed a reduced responsiveness to fructose (blue curve, white dots) but not to sucrose (red curve, white dots). ns, nonsense; w, wild type. n.s.: nonsignificant; **: significant. From Değirmenci et al. (2020). Courtesy of L. Değirmenci. 


\section{3 | Detection of amino acids-AmGr10}

The umami taste is related to the detection of amino acids. The basis for amino acid detection in honey bees is provided by $A m G r 10$ as shown by a study in which this receptor gene was cloned and expressed in Xenopus oocytes or transfected in HEK cells, to obtain two independent measures of receptor sensitivity using electrophysiological recordings (Lim et al., 2019). These recordings showed that AmGrl0 does not confer sensitivity to sweet and bitter tastants but confers sensitivity to a broad spectrum of amino acids such as aspartate, lysine, glutamate, glutamine, asparagine and arginine, and more particularly to L-glutamate and L-aspartate (Lim et al., 2019), which are major components of pollen (Szczęsna, 2006; Figure 3d). As in umami taste perception by humans, responses were enhanced by the addition of purine ribonucleotides such as IMP (inosine-5'-monophosphate) or GMP (Guanine 5'-monophosphate).

AmGrlo is expressed in sensilla chaetica of the galea. Single-sensillum recordings performed on these sensilla indeed showed responses to L-glutamate and L-aspartate, as well as to sucrose (Lim et al., 2019), thus suggesting that one of the four uncharacterized GRNs hosted by these sensilla is specifically tuned to amino acids. The specificity of the other three GRNs was already known: two respond to electrolytes and one to sugars (Whitehead \& Larsen, 1976a). Alternatively, these results could be explained if different GRs were expressed in a single GRN like in mammalian sweet-umami cells (Grant, 2012).

AmGrlo was expressed not only in gustatory hairs located in the mouth parts of the bee but also in the fat body and other internal organs such as the brain and the hypopharyngeal glands (Lim et al., 2019). The distributed internal expression of AmGrlO was confirmed by another study, which focused on the hypopharyngeal glands, brain, and ovaries of nurses (Paerhati et al., 2015). Expression levels were higher than those of foragers and AmGrlO knockdown by dsRNA injection at the nurse stage caused earlier nurse-to-forager transition (Paerhati et al., 2015). Taken together, analyses of the internal expression of $\mathrm{AmGrlO}$ at the adult stage suggest that, besides its role as a peripheral amino acid detector, the receptor encoded by this gene would monitor internal levels of amino acids for nutritional processes that may underlie division of labor.

In conclusion, the receptor encoded by AmGrlo is clearly dedicated to amino acid sensing both at the periphery and internally. The existence of such a receptor in honey bees seems adaptive, given the biological importance of amino acids at multiple levels in this species (see above). What remains to be determined is the mechanistic basis of amino acid sensing by this receptor given its broad tuning. Identifying the structure and/or the molecular features of the amino acids that are recognized by the receptor would be an important goal per se.

\subsection{Detection of bitter substances}

As discussed above, the detection of bitter taste by honey bees remains controversial. So far, no clear evidence for the existence of dedicated bitter-taste receptors has been provided. Some authors have remarked that $\mathrm{AmGr} 4$ and AmGr5 share similarities with the Drosophila DmGr28a/b complex (Robertson \& Wanner, 2006), which was later related to bitter detection after its identification in bitter-taste neurons located in taste sensilla on the legs (Ling et al., 2014) and proboscis (French et al., 2015). Yet the basis for bitter detection in Drosophila is provided by six other GR genes (DmGr32a, DmGr33a, DmGr39a; DmGr66a, DmGr89a and DmGr93a), none of which is directly related to the $D m G r 28 a / b$ complex (Dweck \& Carlson, 2020). Thus, similarity between AmGr4 and $A m G r 5$ and $D m G r 28 a / b$ does not constitute a convincing argument to justify the involvement of the former in bitter perception.

A recent study by Leung et al. (2020) yielded a surprising result in D. melanogaster: three opsin receptor genes (Rhl, $R h 4$ and $R h 7$ ) are expressed in the same GRNs and are required for the detection of a plant-derived bitter substance (aristolochic acid). In addition, the opsin receptor gene $R h 6$ is expressed in bitter-taste GRNS of the fruit fly, where it is responsible for the rejection of cold sucrose solution ( $\mathrm{Li}$ et al., 2020). This suggests that opsins may act as chemosensors or as thermosensors besides their well-known role in vision (Leung \& Montell, 2017). Honey bees possess four opsin genes conferring sensitivity to UV-, blue and green light ranges (1 UV opsin, 1 blue opsin and two green opsins; Velarde et al., 2005; Wakakuwa et al., 2005), but no study has yet investigated their possible role as chemosensors or thermosensors.

Overall, there is no clear evidence supporting the existence of a receptor channel specialized in the detection of bitter tastants in honey bees. Some of the Grs that have not been functionally characterized until now might serve this function. Yet the lack of homology with fruit fly receptor genes that participate in bitter detection casts doubts about the presence of bitter-dedicated receptors. Detection of bitter taste might nevertheless be possible, via other receptor types (e.g., opsin-like) or via its suppressive effect on sugar GRNs (see above).

\section{5 | Detection of salts}

In D. melanogaster, peripheral detection of salts is mediated by a complex system including gustatory-receptor (Grs) and ionotropic-receptor (Irs) genes (Jaeger et al., 2018). Low salt attraction depends primarily on "sweet" neurons expressing Gr64f, with additional input from neurons expressing the ionotropic receptor IR94e, which has no identified ortholog in the 
honey bee (Croset et al., 2010). High-salt avoidance is mediated by "bitter" neurons expressing DmGr66a and a population of glutamatergic neurons expressing the low osmolarity sensor Pickpocket23 (Ppk23). Moreover, when flies are deprived of salt, activation of Ppk23 is suppressed, thus showing a state dependency that is adaptive and conditioned by the insect's needs. In addition, responses of these Ppk23glut neurons require the presence of IR76b (Jaeger et al., 2018), while responses of Gr66a neurons, the other neuronal type mediating high-salt avoidance, do not require it (Jaeger et al., 2018). Responses of Gr64f neurons, which mediate attraction to low-salt concentrations, are completely dependent on IR76b, consistently with its proposed role in sensing low-salt taste (Jaeger et al., 2018). Interestingly, the IR76b-dependent salt responses of Gr64f neurons are sodium specific while those of Ppk23glut GRNs are not. It has also been suggested that IR76b and IR25a may act in a complex to mediate salt taste detection, which is consistent with evidence indicating that IR25a is a broadly expressed co-receptor (Ahn et al., 2017; Benton et al., 2009; Cameron et al., 2010; Chen \& Amrein, 2017).

These results indicate a complex and state-dependent mode of salt detection, involving different salt transduction mechanisms and different classes of GRs and neurons (Jaeger et al., 2018). This may explain why prior reports differed on whether high-salt responses remain intact in IR76b mutants as its suppression and consequences may depend on the GRN type and transduction mechanism affected (Lee et al., 2017; Zhang et al., 2013).

In honey bees, GRNs responding to saline solutions definitely exist as electrophysiological and behavioral evidence indicates the presence of molecular-receptor mechanisms dedicated to salt detection (see above). Although it is conceivable that at least one of the GRNs hosted in gustatory sensilla is dedicated to saline solutions, so far no GR could be specifically ascribed to salt detection. Honey bees seem to have less receptors to sense salts than fruit flies, since no orthologs of Gr66a, IR94e, and ppk23 have been found in the bee genome. Honey bees express only three ppks (ppk19 and ppk28, sodium channel protein Nach) whose functions are still unknown. Yet they possess an ortholog to IR76b (Croset et al., 2010), which-as seen above-is required for both low-salt sensing and highsalt sensing and is expressed in all GRNs tested at the level of the fly labellum (Jaeger et al., 2018). Detection of saline solutions could be mediated either by specific GRs or by sweetsensing neurons expressing this IR as in the fruit fly. If and how AmIR76b participates in salt taste detection in the honey bee remains to be determined.

\section{6 | Detection of acids}

As no electrophysiological evidence exists supporting the existence of GRNs responding to acids in the honey bee, the molecular basis of acid detection remains speculative in this insect. Bees might detect acids while foraging using IR25a and IR76a, which have corresponding orthologs in the fruit fly where they mediate acid detection for oviposition preference (Chen \& Amrein, 2014). Yet the role of these IRs is unknown in honey bees.

\section{7 | SENSING TASTANTS WITH IRS}

IRs involved in gustation have been studied in the fruit fly but not in the honey bee. Gustatory IRs can be found in sensilla broadly distributed along the body of $D$. melanogaster, including the labellum, legs, pharynx, and wings (Koh et al., 2014). In the fruit fly, IR76b is necessary for low salt detection (Zhang et al., 2013), but this receptor also drives avoidance of high salt (Jaeger et al., 2018; Lee et al., 2017). Interestingly, both IR76b and IR25a are expressed in bitter and sweet GRNs (Benton et al., 2009; Croset et al., 2010) and more recently they have been also identified in acid-sensing GRNs located in tarsal sensilla (Chen \& Amrein, 2017). IR76b and IR25a expressed in sweet GRNs are required for fatty-acid detection (Ahn et al., 2017) and also for detecting sour taste in acid-sensing GRNs (Chen \& Amrein, 2017).

In the honey bee, genome, Sadd et al. (2015) identified 21 IRs. A similar number (22) was reported for the genome of the bumble bee $B$. terrestris (Sadd et al., 2015). So far, their functions, both in honey bees and in bumble bees, remain unknown. Expression analyses by means of RT-PCR have been conducted in the antennae and brain of the honey bee for only six $\operatorname{Ir}$ genes (Ir8a, Ir25a, Ir68a, Ir75u, Ir76b and Ir93a) because they are orthologs of $D$. melanogaster Ir genes (Croset et al., 2010). The mRNA of Ir68a and Ir75u was expressed in both the brain and the antennae of the honey bee. For instance, IR8a forms a functional subunit with IR64a that acts as an olfactory receptor mediating odor detection (Ai et al., 2013). IR25a, IR68a, and IR93a are required for humidity sensing (Enjin et al., 2016; Knecht et al., 2017). Also, IR25a and IR21 a mediate thermosensation (Ni et al., 2016). Their localization in antennal sensilla of the honey bee is consistent with a role of these appendages for multimodal sensory detection. The functions ensured by these IRs in bees remain to be determined. Their participation in sensing salts as well as substances such as acids and fatty acids, for which not much is known in the taste biology of bees, could be highly relevant.

\section{8 | CONCLUSION AND PERSPECTIVES}

The multiple levels of analysis of bee gustatory perception presented here highlight the complexity of honey bees' 
gustatory world and of the neural and molecular mechanisms mediating taste perception in these insects. Bees do not necessarily live in an impoverished gustatory world despite the specialization of some colony members on floral products. Task specialization within the hive, which is a fundamental feature of the social life style of bees, results in different bees collecting different products, which are not always derived from flowers. These include water with different mineral contents, resins, and even feces (Mattila et al., 2020). Moreover, we have focused on traditional tastants such as sugars, salts, acids, amino acids, and bitter substances, but the taste receptors of bees might also be used to sense longchain fatty molecules such as cuticular hydrocarbons and low-volatile pheromones. These gustatory dimensions need to be further explored.

An important conclusion that can be drawn from our review is that "not all the bees in the colony are equal". Worker bees within a hive differ in terms of their genetic background as several patrilines can coexist within a hive. Accordingly, bees from different patrilines may differ in their behavioral and/or physiological responses to identical or similar events. Thus, in analyzing taste and taste-related behaviors, caution should be taken to specify which kind of bees are used and which are the reasons justifying this choice as gustatory and feeding processes and motivation may vary dramatically between bees. Taste processes and sensitivity may not only vary with age but also with season and task specialization. Thus, the common practice of capturing bees indiscriminately at a hive is not recommendable as it excludes any possible control of the kind of bee used in the experiments. Addressing questions on appetitive taste perception in winter bees, and extrapolating them to summer bees, or even worse, to all bees, could be misleading as winter and summer bees differ dramatically in their energy budgets, body reserves, and neurohormonal regulation (Behrends \& Scheiner, 2010). Similarly, absence of control of the kind of bee used (guard, nurse, forager, etc.) may lead to erroneous conclusions as taste sensitivity may vary with task specialization. From this perspective, research agendas addressing if and how molecular taste receptors change their expression levels quantitatively but also qualitatively according to these factors would be extremely important to understand the link between task specialization, age, season and taste sensitivity, among others (Pankiw \& Page, 1999; Pankiw et al., 2001; Scheiner et al., 2004; Tsuruda \& Page, 2009). Another fundamental question that has been poorly addressed so far with respect to honey bee taste is the role of experience and the plasticity in shaping taste responses. Besides the existence of learning protocols in which taste is deprived of any reinforcement function to be presented as a stimulus to be learned and memorized (Guiraud et al., 2018), further questions on the effect of experience on molecular receptor expression need to be addressed. In the olfactory domain, it has been shown that odor learning changes the expression levels of olfactory receptors in honey bees (Claudianos et al., 2014). The olfactory receptor AmOr151, which is a broadly tuned receptor binding floral odorants such as linalool, and AmOr11, the specific receptor for the queen pheromone 9-oxo-decenoic acid, were both significantly downregulated after honeybees had learned these odorants in the olfactory PER conditioning assay. Long-term odor memory was essential for inducing these changes, suggesting that the molecular mechanisms involved in olfactory memory also regulate olfactory receptor expression at the periphery. Changes in taste receptor expression linked to repeated exposures to certain tastes may also occur, thus adding an additional source of variability that needs to be considered and evaluated.

Behavioral methods for analyzing taste responses in bees are diverse, but many of them have used the appetitive response of PER. This strategy is problematic as it makes dissociating taste from ingestive processes difficult. When a bee stops responding to a mixture of sucrose and a given tastant, straightforward interpretations that such response ceasing is due to the aversive nature of the tastant added to the sucrose solution are incautious. A variety of perceptual phenomena may underlie this phenomenon, from the inhibition of sucrose receptors by the added tastant to a change in taste that is not aversive but does not match a forager's expectation of highquality sucrose solution. This problem renders difficult the analysis of mixtures of sucrose solution with other tastants (Ayestaran et al., 2010; Bertazzini et al., 2010; Desmedt et al., 2016; von Frisch, 1934; Hagler \& Buchmann, 1993; Kim \& Smith, 2000), which rely on the appetitive motivation of the bees to respond to food reward. From this perspective, the development of new protocols to study taste perception and discrimination, which try to reduce significantly the reinforcing function of a tastant is mandatory to advance our understanding of taste processes in bees.

The publication of the honey bee genome (Honeybee Genome Sequencing Consortium, 2006) expanded considerably our knowledge on the gustatory sense of bees, but further investigations are needed, guided by hypothesis derived with caution from this molecular data base. From the GR genes identified in the bee genome, only four have been characterized. Seven AmGrs remain to be characterized, which may allow solving pending questions and controversies such as the existence of bitter receptors or the process of fat taste detection. These receptors seem to build a unique lineage separating hymenopterans from other insect groups.

The development of new methods such as CRISPR/Cas9 or RNAi, which can be applied to the honey bee (Değirmenci et al., 2020; Guo et al., 2018; Wang et al., 2013), could provide valuable ways for addressing taste receptor function. Combining these strategies of receptor knock-down with behavioral and/or electrophysiological analyses requires time and considerable efforts but appears at the present time as 
a privileged choice for studying GR genes in the honey bee. These molecular techniques could also serve for characterizing other mechanisms and receptors involved in taste perception in the bee. If information about Grs is still scarce, our current knowledge on the IRs of the bee is even more limited. The same applies to other types of receptors that might be used by bees to sense tastes (opsins, TRPs, ppks, etc.). Which functions they mediate and what is their gustatory tuning remains to be determined.

Another dimension of taste processing that requires thoughtful investigation is the central neuromodulation of taste processing pathways. Another reason for variability in gustatory responses may be the top-down modulation of the activity of GRNs and higher-order gustatory pathways. Bees, like most animals, are subjected to central neuromodulatory processes, which are crucial to define motivational states and which set the occasion for performing specific behaviors. Neurotransmitters such as biogenic amines (e.g., dopamine, octopamine, serotonin, among others) released in the central nervous system can act as facilitators or depressors of behavior or as instructive signals during learning and play a crucial role for an animal responsiveness toward specific sensory stimuli (Mercer \& Menzel, 1982; Tedjakumala et al., 2014). For instance, appetitive responsiveness of bees, evaluated through PER to increasing concentrations of sucrose solution, is enhanced by octopamine (Scheiner et al., 2002, 2006) and is also influenced by tyramine (Scheiner et al., 2017). Other factors have been shown to modulate appetitive responsiveness via biogenic amines (e.g., pheromones; Baracchi et al., 2017, 2020), thus showing their importance for appetitive motivation.

These molecules may also act at the peripheral level, changing the sensitivity of receptors. For instance, in the male of the silk moth B. mori, octopamine increases the amplitude of receptor and action potentials elicited by the pheromone components Bombykol and Bombykal (Pophof, 2002). This shows that central neurotransmitters can have a modulatory action at the peripheral level, changing the responses of sensory receptors. Top-down modulation of gustatory processes has been shown in vertebrates; in the mouse, labeledline circuits transmitting sweet and bitter signals from the tongue to the cortex are modulated by top-down processes (Jin et al., 2021). In this case, the gustatory cortex and the amygdala exert positive and negative feedback onto incoming bitter and sweet signals from the periphery in the brainstem. Top-down modulation of peripheral responses to taste has been shown in fruit flies where orthogonal neuromodulatory cascades control oppositely sweet and bitter peripheral taste sensitivity (Inagaki et al., 2014). Starved animals exhibit enhanced sugar sensitivity and decreased bitter sensitivity, allowing them to accept food resources that would be otherwise rejected. Bitter sensitivity is independently modulated during food deprivation, in the opposite direction as sugar sensitivity. While sugar sensitivity is increased via the neuropeptide $\mathrm{F}(\mathrm{dNPF})$ and dopaminergic signaling acting on sweet taste receptors, bitter sensitivity is reduced via the action of the adipokinetic hormone (AKH), the short neuropeptide $\mathrm{F}$ (sNPF) and GABA-ergic neurons inhibiting bitter-taste receptors (Inagaki et al., 2014). In this way, state-intensitydependent, reciprocal regulation of appetitive and aversive peripheral gustatory sensitivity permits flexible, adaptive feeding decisions (Inagaki et al., 2014). Thus, motivational factors change the levels of neurotransmitters in the insect brain and affect thereby both the activity of taste receptors and eventually their expression levels. In consequence, the analysis of taste processes would benefit from considering factors that may alter the ratio of neurotransmitters in the brain such as the genetic background, hunger state, nutrient needs, age, social cast, or season (Harris \& Woodring, 1992; Schulz et al., 2002; Taylor et al., 1992). We suggest here that neurotransmitters and neuropeptides can exert a top-down control on GRs and expression levels of Grs, which can be an additional explanation for the variability observed in behavioral and electrophysiological experiments addressing gustatory responses.

Besides the neuromodulatory action exerted by neurotransmitters and neuropeptides, gustatory sensitivity can also vary with the diet consumed by the insects. In the locust, for instance, a diet rich in some nutrients (e.g., amino acids) results in an increase of their levels in the hemolymph and in a concomitant decrease in the sensitivity and gustatory responses to the abundant substances (Abisgold \& Simpson, 1988; Simpson \& Simpson, 1992). The mechanism by which this nutrient increase changes the sensitivity of GRNs is still unclear but it was suggested that the abundant nutrients in the hemolymph could enter into receptor hemolymph of the sensilla and bind to GRs, inducing thereby an adaptation of GRNs and a decrease of sensitivity (Abisgold \& Simpson, 1988; Simpson \& Simpson, 1992). Exploring this possibility in honey bees should take into account both nutrient reserves in the fat body, which may decrease the impact of artificial diets, and the foragers' social life as ingested nutrients may be transiently stored in the crop for delivery in the hive, without being fully consumed and metabolized.

Finally, in the light of vivid debates on current agricultural practices employed by humans and a resulting massive, worldwide mortality of honey bee colonies (the so-called "colony collapse disorder") induced by multiple factors including the indiscriminate use of agrochemicals, it is now crucial to better understand the gustatory world of honey bees. Some studies already assessed the preference of free-flying bees when given the choice between pure sugar solutions and solutions contaminated with different types of agrochemicals (Arce et al., 2018; Kessler et al., 2015; Liao et al., 2017). Yet more work is required to answer the crucial socioeconomic question of if and how 
pesticides and other molecules released in the environment (e.g., weed-killers or even sanitary products for veterinary use) affect per se gustatory responses, the activity of gustatory neurons and their molecular receptors (Kessler et al., 2015). Addressing this question with the tools and approaches described in this article would add a fundamental dimension to these debates, uncovering unknown and possibly unsuspected effects of these molecules on the behavior and neurophysiology of bees.

\section{ACKNOWLEDGEMENTS}

We thank H. M. Robertson, N. D. Tsutsui, and B. M. Sadd for providing protein sequences of the GRs of L. humile, $N$. vitripennis and of AmGr11, AmGr12. We thank the French National Research Agency ANR (Project APITASTE ANR18-CE37-0021), the CNRS, and the University Paul Sabatier for funding. M.G. also thanks the Institut Universitaire de France for support.

\section{CONFLICT OF INTERESTS}

The authors declare no conflict of interest.

\section{AUTHOR CONTRIBUTIONS}

L. Bestea, conceptualization, writing-original draft, writingreview and editing; A. Réjaud, phylogenetic tree reconstruction, writing-original draft, writing-review and editing; J.-C. Sandoz, funding acquisition, writing-review and editing; J. Carcaud, writing-review and editing; M. Giurfa, conceptualization, funding acquisition, writing-review and editing; M.G. de Brito Sanchez, conceptualization, funding acquisition, writing-review and editing.

\section{PEER REVIEW}

The peer review history for this article is available at https:// publons.com/publon/10.1111/ejn.15265.

\section{ORCID}

Louise Bestea iD https://orcid.org/0000-0002-0440-1122 Martin Giurfa iD https://orcid.org/0000-0001-7173-769X Maria Gabriela de Brito Sanchez (iD https://orcid. org/0000-0001-6940-8088

\section{REFERENCES}

Abisgold, J. D., \& Simpson, S. J. (1988). The effect of dietary protein levels and haemolymph composition on the sensitivity of the maxillary palp chemoreceptors of locusts. Journal of Experimental Biology, 135(1), 215-229. https://doi.org/10.1242/JEB.135.1.215

Adams, C. M., Anderson, M. G., Motto, D. G., Price, M. P., Johnson, W. A., \& Welsh, M. J. (1998). Ripped pocket and pickpocket, novel Drosophila DEG/ENaC subunits expressed in early development and in mechanosensory neurons. Journal of Cell Biology, 140(1), 143-152. https://doi.org/10.1083/jcb.140.1.143

Afroz, A., Howlett, N., Shukla, A., Ahmad, F., Batista, E., Bedard, K., Payne, S., Morton, B., Mansfield, J. H., \& Glendinning, J. I. (2013).
Gustatory receptor neurons in Manduca sexta contain a TrpA1dependent signaling pathway that integrates taste and temperature. Chemical Senses, 38(7), 605-617. https://doi.org/10.1093/chemse/ bjt032

Agnihotri, A. R., Roy, A. A., \& Joshi, R. S. (2016). Gustatory receptors in Lepidoptera: Chemosensation and beyond. Insect Molecular Biology, 25(5), 519-529. https://doi.org/10.1111/imb.12246

Aguiar, J. M. R. B. V., Roselino, A. C., Sazima, M., \& Giurfa, M. (2018). Can honey bees discriminate between floral-fragrance isomers? Journal of Experimental Biology, 221(14), jeb180844. https://doi. org/10.1242/jeb.180844

Ahn, J. E., Chen, Y., \& Amrein, H. (2017). Molecular basis of fatty acid taste in Drosophila. eLife, 6, e30115. https://doi.org/10.7554/ eLife. 30115

Ai, M., Blais, S., Park, J. Y., Min, S., Neubert, T. A., \& Suh, G. S. B. (2013). Ionotropic glutamate receptors IR64a and IR8a form a functional odorant receptor complex in vivo in Drosophila. Journal of Neuroscience, 33(26), 10741-10749. https://doi.org/10.1523/ JNEUROSCI.5419-12.2013

Alves, G., Sallé, J., Chaudy, S., Dupas, S., \& Manière, G. (2014). High- $\mathrm{NaCl}$ perception in Drosophila melanogaster. Journal of Neuroscience, 34(33), 10884-10891. https://doi.org/10.1523/ JNEUROSCI.4795-13.2014

Arce, A. N., Ramos Rodrigues, A., Yu, J., Colgan, T. J., Wurm, Y., \& Gill, R. J. (2018). Foraging bumblebees acquire a preference for neonicotinoid-treated food with prolonged exposure. Proceedings of the Royal Society of London B: Biological Sciences, 285(1885), 20180655. https://doi.org/10.1098/rspb.2018.0655

Avarguès-Weber, A., de Brito Sanchez, M. G., Giurfa, M., \& Dyer, A. G. (2010). Aversive reinforcement improves visual discrimination learning in free-flying honeybees. PLoS ONE, 5(10), e15370. https://doi.org/10.1371/journal.pone.0015370

Avarguès-Weber, A., Deisig, N., \& Giurfa, M. (2011). Visual cognition in social insects. Annual Review of Entomology, 56(1), 423-443. https://doi.org/10.1146/annurev-ento-120709-144855

Avarguès-Weber, A., Mota, T., \& Giurfa, M. (2012). New vistas on honey bee vision. Apidologie, 43(3), 244-268. https://doi.org/10.1007/ s13592-012-0124-2

Ayestaran, A., Giurfa, M., \& de Brito Sanchez, M. G. (2010). Toxic but drank: Gustatory aversive compounds induce post-ingestional malaise in harnessed honeybees. PLOS ONE, 5(10), e15000. https:// doi.org/10.1371/journal.pone.0015000

Bachman, W. W., \& Waller, G. (1977). Honeybee responses to sugar solutions of different compositions. Journal of Apicultural Research, 16(4), 165-169. https://doi.org/10.1080/00218839.1977.11099882

Baracchi, D., Cabirol, A., Devaud, J. M., Haase, A., d'Ettorre, P., \& Giurfa, M. (2020). Pheromone components affect motivation and induce persistent modulation of associative learning and memory in honey bees. Communications Biology, 3(1), 1-9. https://doi. org/10.1038/s42003-020-01183-x

Baracchi, D., Devaud, J. M., D'Ettorre, P., \& Giurfa, M. (2017). Pheromones modulate reward responsiveness and non-associative learning in honey bees. Scientific Reports, 7(1), 1-9. https://doi. org/10.1038/s41598-017-10113-7

Behrends, A., \& Scheiner, R. (2010). Learning at old age: A study on winter bees. Frontiers in Behavioral Neuroscience, 4, 15. https://doi. org/10.3389/fnbeh.2010.00015

Ben-Shahar, Y. (2011). Sensory functions for degenerin/epithelial sodium channels (DEG/ENaC). Advances in Genetics, 76, 1-26. https://doi.org/10.1016/B978-0-12-386481-9.00001-8 
Benton, R., Sachse, S., Michnick, S. W., \& Vosshall, L. B. (2006) Atypical membrane topology and heteromeric function of Drosophila odorant receptors in vivo. PLoS Biology, 4(2), 240-257. https://doi.org/10.1371/journal.pbio.0040020

Benton, R., Vannice, K. S., Gomez-Diaz, C., \& Vosshall, L. B. (2009). Variant ionotropic glutamate receptors as chemosensory receptors in Drosophila. Cell, 136(1), 149-162. https://doi.org/10.1016/j. cell.2008.12.001

Bertazzini, M., Medrzycki, P., Bortolotti, L., Maistrello, L., \& Forlani, G. (2010). Amino acid content and nectar choice by forager honeybees (Apis mellifera L.). Amino Acids, 39(1), 315-318. https://doi. org/10.1007/s00726-010-0474-x

Bhagavan, S., \& Smith, B. H. (1997). Olfactory conditioning in the honey bee, Apis mellifera: Effects of odor intensity. Physiology and Behavior, 61(1), 107-117. https://doi.org/10.1016/S0031 -9384(96)00357-5

Bitterman, M. E., Menzel, R., Fietz, A., \& Schäfer, S. (1983). Classical conditioning of proboscis extension in honeybees (Apis mellifera). Journal of Comparative Psychology, 97(2), 107-119. https://doi.org /10.1037/0735-7036.97.2.107

Boeckh, J. (1962). Elektrophysiologische Untersuchungen an einzelnen Geruchsrezeptoren auf den Antennen des Totengräbers (Necrophorus, Coleoptera). Zeitschrift Für Vergleichende Physiologie, 46(2), 212-248. https://doi.org/10.1007/BF00341551

Boeckh, J., Kaissling, K. E., \& Schneider, D. (1965). Insect olfactory receptors. Cold Spring Harbor Symposia on Quantitative Biology, 30, 263-280. https://doi.org/10.1101/SQB.1965.030.01.028

Bonabeau, E., Theraulaz, G., \& Deneubourg, J. L. (1996). Quantitative study of the fixed threshold model for the regulation of division of labour in insect societies. Proceedings of the Royal Society of London B: Biological Sciences, 263(1376), 1565-1569. https://doi. org/10.1098/rspb.1996.0229

Bonasio, R., Zhang, G., Ye, C., Mutti, N. S., Fang, X., Qin, N., Donahue, G., Yang, P., Li, Q., Li, C., Zhang, P., Huang, Z., Berger, S. L., Reinberg, D., Wang, J., \& Liebig, J. (2010). Genomic comparison of the ants Camponotus floridanus and Harpegnathos saltator. Science, 329(5995), 1068-1071. https://doi.org/10.1126/scien ce. 1192428

Bonoan, R. E., Tai, T. M., Tagle Rodriguez, M., Feller, L., Daddario, S. R., Czja, R. A., ... Straks, P. T. (2017). Seasonality of salt foraging in honey bees (Apis mellifera). Ecological Entomology, 42(2), 195201. https://doi.org/10.1111/een.12375

Brown, M. J. F., \& Paxton, R. J. (2009). The conservation of bees: A global perspective. Apidologie, 40(3), 410-416. https://doi. org/10.1051/apido/2009019

Burden, C. M., Morgan, M. O., Hladun, K. R., Amdam, G. V., Trumble, J. J., \& Smith, B. H. (2019). Acute sublethal exposure to toxic heavy metals alters honey bee (Apis mellifera) feeding behavior. Scientific Reports, 9(1), 1-10. https://doi.org/10.1038/s41598-019-40396-x

Butler, C. G. (1940). The choice of drinking water by the honeybee. Journal of Experimental Biology, 17(3), 253-261. https://doi. org/10.1242/jeb.17.3.253

Cameron, P., Hiroi, M., Ngai, J., \& Scott, K. (2010). The molecular basis for water taste in Drosophila. Nature, 465(7294), 91-95. https://doi. org/10.1038/nature09011

Carcaud, J., Giurfa, M., \& Sandoz, J. C. (2015). Differential combinatorial coding of pheromones in two olfactory subsystems of the honey bee brain. Journal of Neuroscience, 35(10), 4157-4167. https://doi. org/10.1523/JNEUROSCI.0734-14.2015
Chandrashekar, J., Kuhn, C., Oka, Y., Yarmolinsky, D. A., Hummler, E., Ryba, N. J. P., \& Zuker, C. S. (2010). The cells and peripheral representation of sodium taste in mice. Nature, 464(7286), 297-301. https://doi.org/10.1038/nature08783

Chen, Y., \& Amrein, H. (2014). Enhancing perception of contaminated food through acid-mediated modulation of taste neuron responses. Current Biology, 24(17), 1969-1977. https://doi.org/10.1016/j. cub.2014.07.069

Chen, Y., \& Amrein, H. (2017). Ionotropic receptors mediate Drosophila oviposition preference through sour gustatory receptor neurons. Current Biology, 27(18), 2741-2750.e4. https://doi.org/10.1016/j. cub.2017.08.003

Chen, Z., Wang, Q., \& Wang, Z. (2010). The amiloride-sensitive epithelial $\mathrm{Na}^{+}$channel PPK28 is essential for Drosophila gustatory water reception. Journal of Neuroscience, 30(18), 6247-6252. https://doi. org/10.1523/JNEUROSCI.0627-10.2010

Claudianos, C., Lim, J., Young, M., Yan, S., Cristino, A. S., Newcomb, R. D., Gunasekaran, N., \& Reinhard, J. (2014). Odor memories regulate olfactory receptor expression in the sensory periphery. European Journal of Neuroscience, 39(10), 1642-1654. https://doi. org/10.1111/ejn.12539

Clyne, P. J., Warr, C. G., \& Carlson, J. R. (2000). Candidate taste receptors in Drosophila. Science, 287(5459), 1830-1834. https://doi. org/10.1126/science.287.5459.1830

Cook, S. M., Awmack, C. S., Murray, D. A., \& Williams, I. H. (2003). Are honey bees' foraging preferences affected by pollen amino acid composition? Ecological Entomology, 28(5), 622-627. https://doi. org/10.1046/j.1365-2311.2003.00548.x

Cook, S. M., Sandoz, J.-C., Martin, A. P., Murray, D. A., Poppy, G. M., \& Williams, I. H. (2005). Could learning of pollen odours by honey bees (Apis mellifera) play a role in their foraging behaviour? Physiological Entomology, 30(2), 164-174. https://doi. org/10.1111/j.1365-3032.2005.00445.x

Croset, V., Rytz, R., Cummins, S. F., Budd, A., Brawand, D., Kaessmann, H., Gibson, T. J., \& Benton, R. (2010). Ancient protostome origin of chemosensory ionotropic glutamate receptors and the evolution of insect taste and olfaction. PLoS Genetics, 6(8), e1001064. https:// doi.org/10.1371/journal.pgen.1001064

Croset V., Schleyer M., Arguello J. R., Gerber B., \& Benton R. (2016). A molecular and neuronal basis for amino acid sensing in the Drosophila larva. Scientific Reports, 6(1), 34871. https://doi. org/10.1038/srep34871

Dahanukar, A., Lei, Y. T., Kwon, J. Y., \& Carlson, J. R. (2007). Two Gr genes underlie sugar reception in Drosophila. Neuron, 56(3), 503516. https://doi.org/10.1016/j.neuron.2007.10.024

de Brito Sanchez, G., \& Giurfa, M. (2011). A comparative analysis of neural taste processing in animals. Philosophical Transactions of the Royal Society London B: Biological Sciences, 366(1574), 21712180. https://doi.org/10.1098/rstb.2010.0327

de Brito Sanchez, M. G. (2011). Taste perception in honey bees. Chemical Senses, 36(8), 675-692. https://doi.org/10.1093/chemse/ bjr040

de Brito Sanchez, M. G., Giurfa, M., de Paula Mota, T. R., \& Gauthier, M. (2005). Electrophysiological and behavioural characterization of gustatory responses to antennal 'bitter' taste in honeybees. European Journal of Neuroscience, 22(12), 3161-3170. https://doi. org/10.1111/j.1460-9568.2005.04516.x

de Brito Sanchez, M. G., Lorenzo, E., Su, S., Liu, F., Zhan, Y., \& Giurfa, M. (2014). The tarsal taste of honey bees: Behavioral and 
electrophysiological analyses. Frontiers in Behavioral Neuroscience, 8, 25. https://doi.org/10.3389/fnbeh.2014.00025

de Brito Sanchez, M. G., Serre, M., Avarguès-Weber, A., Dyer, A. G., \& Giurfa, M. (2015). Learning context modulates aversive taste strength in honey bees. Journal of Experimental Biology, 218(6), 949-959. https://doi.org/10.1242/jeb.117333

de Groot, A. P. (1952). Amino acid requirements for growth of the honeybee (Apis mellifica L.). Experientia, 8(5), 192-194. https://doi. org/10.1007/BF02173740

Değirmenci, L., Geiger, D., Rogé Ferreira, F. L., Keller, A., Krischke, B., Beye, M., Steffan-Dewenter, I., \& Scheiner, R. (2020). CRISPR/ Cas9 mediated mutations as a new tool for studying taste in honeybees. Chemical Senses, 45(8), 655-666. https://doi.org/10.1093/ chemse/bjaa063

Değirmenci, L., Thamm, M., \& Scheiner, R. (2018). Responses to sugar and sugar receptor gene expression in different social roles of the honeybee (Apis mellifera). Journal of Insect Physiology, 106, 6570. https://doi.org/10.1016/j.jinsphys.2017.09.009

DeSimone, J. A., Lyall, V., Heck, G. L., \& Feldman, G. M. (2001). Acid detection by taste receptor cells. Respiration Physiology, 129(1-2), 231-245. https://doi.org/10.1016/S0034-5687(01)00293-6

Desmedt, L., Hotier, L., Giurfa, M., Velarde, R., \& de Brito Sanchez, M. G. (2016). Absence of food alternatives promotes risk-prone feeding of unpalatable substances in honey bees. Scientific Reports, 6(1), 1-11. https://doi.org/10.1038/srep31809

Drescher, N., Klein, A.-M., Schmitt, T., \& Leonhardt, S. D. (2019). A clue on bee glue: New insight into the sources and factors driving resin intake in honeybees (Apis mellifera). PLoS ONE, 14(2), e0210594. https://doi.org/10.1371/journal.pone.0210594

Dunipace, L., Meister, S., McNealy, C., \& Amrein, H. (2001). Spatially restricted expression of candidate taste receptors in the Drosophila gustatory system. Current Biology, 11(11), 822-835. https://doi. org/10.1016/S0960-9822(01)00258-5

Dweck, H. K. M., \& Carlson, J. R. (2020). Molecular logic and evolution of bitter taste in Drosophila. Current Biology, 30(1), 17-30. https://doi.org/10.1016/j.cub.2019.11.005

Enjin, A., Zaharieva, E. E., Frank, D. D., Mansourian, S., Suh, G. S. B., Gallio, M., \& Stensmyr, M. C. (2016). Humidity sensing in Drosophila. Current Biology, 26(10), 1352-1358. https://doi. org/10.1016/j.cub.2016.03.049

Esslen, J., \& Kaissling, K. E. (1976). Number and distribution of the sensilla on the antennal flagellum of the honeybee (Apis mellifera L.). Zoomorphologie, 83(3), 227-251. https://doi.org/10.1007/ BF00993511

French, A., Agha, M. A., Mitra, A., Yanagawa, A., Sellier, M. J., \& MarionPoll, F. (2015). Drosophila bitter taste(s). Frontiers in Integrative Neuroscience, 9, 58. https://doi.org/10.3389/fnint.2015.00058

Fujii, S., Yavuz, A., Slone, J., Jagge, C., Song, X., \& Amrein, H. (2015). Drosophila sugar receptors in sweet taste perception, olfaction, and internal nutrient sensing. Current Biology, 25(5), 621-627. https:// doi.org/10.1016/j.cub.2014.12.058

Gage, S. L., Calle, S., Jacobson, N., Carroll, M., \& DeGrandi-Hoffman, G. (2020). Pollen alters amino acid levels in the honey bee brain and this relationship changes with age and parasitic stress. Frontiers in Neuroscience, 14, 231. https://doi.org/10.3389/fnins.2020.00231

Ganguly, A., Pang, L., Duong, V. K., Lee, A., Schoniger, H., Varady, E., \& Dahanukar, A. (2017). A molecular and cellular context-dependent role for Ir76b in detection of amino acid taste. Cell Reports, 18(3), 737-750. https://doi.org/10.1016/j.celrep.2016.12.071
Getz, W. M., \& Smith, K. B. (1987). Olfactory sensitivity and discrimination of mixtures in the honeybee Apis mellifera. Journal of Comparative Physiology A, 160(2), 239-245. https://doi. org/10.1007/BF00609729

Giurfa, M., \& Malun, D. (2004). Associative mechanosensory conditioning of the proboscis extension reflex in honeybees. Learning and Memory, 11(3), 294-302. https://doi.org/10.1101/lm.63604

Giurfa, M., \& Sandoz, J. C. (2012). Invertebrate learning and memory: Fifty years of olfactory conditioning of the proboscis extension response in honeybees. Learning and Memory, 19(2), 54-66. https:// doi.org/10.1101/lm.024711.111

Glavinic, U., Stankovic, B., Draskovic, V., Stevanovic, J., Petrovic, T., Lakic, N., \& Stanimirovic, Z. (2017). Dietary amino acid and vitamin complex protects honey bee from immunosuppression caused by Nosema ceranae. PLoS ONE, 12(11), e0187726. https://doi. org/10.1371/journal.pone.0187726

Goulson, D. (2013). Review: An overview of the environmental risks posed by neonicotinoid insecticides. Journal of Applied Ecology, 50(4), 977-987. https://doi.org/10.1111/1365-2664.12111

Goulson, D., Lye, G. C., \& Darvill, B. (2008). Decline and conservation of bumble bees. Annual Review of Entomology, 53(1), 191-208. https://doi.org/10.1146/annurev.ento.53.103106.093454

Goulson, D., Nicholls, E., Botias, C., \& Rotheray, E. L. (2015). Bee declines driven by combined stress from parasites, pesticides, and lack of flowers. Science, 347(6229), https://doi.org/10.1126/scien ce. 1255957

Grant, J. (2012). Tachykinins stimulate a subset of mouse taste cells. PLoS ONE, 7(2), e31697. https://doi.org/10.1371/journ al.pone.0031697

Guiraud, M., Hotier, L., Giurfa, M., \& de Brito Sanchez, M. G. (2018). Aversive gustatory learning and perception in honey bees. Scientific Reports, 8(1), 1-13. https://doi.org/10.1038/s41598-018-19715-1

Guo, X., Wang, Y., Sinakevitch, I., Lei, H., \& Smith, B. H. (2018). Comparison of RNAi knockdown effect of tyramine receptor 1 induced by dsRNA and siRNA in brains of the honey bee, Apis mellifera. Journal of Insect Physiology, 111, 47-52. https://doi. org/10.1016/j.jinsphys.2018.10.005

Hagler, J. R., \& Buchmann, S. L. (1993). Honey bee (Hymenoptera: Apidae) foraging responses to phenolic-rich nectars. Journal of the Kansas Entomological Society, 66(2), 223-230.

Hansson, B. S., Hallberg, E., Löfstedt, C., \& Steinbrecht, R. A. (1994). Correlation between dendrite diameter and action potential amplitude in sex pheromone specific receptor neurons in male Ostrinia nubilalis (Lepidoptera: Pyralidae). Tissue and Cell, 26(4), 503-512. https://doi.org/10.1016/0040-8166(94)90003-5

Harborne, J. B. (1994). Introduction to Ecological Biochemistry (4th ed., pp. 1-384). Academic Press.

Harris, J. W., \& Woodring, J. (1992). Effects of stress, age, season, and source colony on levels of octopamine, dopamine and serotonin in the honey bee (Apis mellifera L.) brain. Journal of Insect Physiology, 38(1), 29-35. https://doi.org/10.1016/0022-1910(92)90019-A

Haupt, S. S. (2004). Antennal sucrose perception in the honey bee (Apis mellifera L.): Behaviour and electrophysiology. Journal of Comparative Physiology A, 190(9), 735-745. https://doi. org/10.1007/s00359-004-0532-5

Hill C. A., Fox A. N., Pitts R. J., Kent L. B., Tan P. L., Chrystal M. A., \& Zwiebel L. J. (2002). G Protein-Coupled Receptors in Anopheles gambiae. Science, 298(5591), 176-178. https://doi.org/10.1126/ science. 1076196 
Hiroi, M., Marion-Poll, F., \& Tanimura, T. (2002). Differentiated response to sugars among labellar chemosensilla in Drosophila. Zoological Science, 19(9), 1009-1018. https://doi.org/10.2108/ zsj.19.1009

Hiroi, M., Meunier, N., Marion-Poll, F., \& Tanimura, T. (2004). Two antagonistic gustatory receptor neurons responding to sweet-salty and bitter taste in Drosophila. Journal of Neurobiology, 61(3), 333342. https://doi.org/10.1002/neu.20063

Honeybee Genome Sequencing Consortium. (2006). Insights into social insects from the genome of the honeybee Apis mellifera. Nature, 443(7114), 931-949. https://doi.org/10.1038/nature05260

Inagaki, H. K., Panse, K. M., \& Anderson, D. J. (2014). Independent, reciprocal neuromodulatory control of sweet and bitter taste sensitivity during starvation in Drosophila. Neuron, 84(4), 806-820. https:// doi.org/10.1016/j.neuron.2014.09.032

Jaeger, A. H., Stanley, M., Weiss, Z. F., Musso, P. Y., Chan, R. C. W., Zhang, H., ... Gordon, M. D. (2018). A complex peripheral code for salt taste in Drosophila. eLife, 7, e37167. https://doi.org/10.7554/ eLife.37167

Jiao, Y., Moon, S. J., Wang, X., Ren, Q., \& Montell, C. (2008). Gr64f is required in combination with other gustatory receptors for sugar detection in Drosophila. Current Biology, 18(22), 1797-1801. https:// doi.org/10.1016/j.cub.2008.10.009

Jin, H., Fishman, Z. H., Ye, M., Wang, L., \& Zuker, C. S. (2021). Topdown control of sweet and bitter taste in the mammalian brain. Cell, 184(1), 257-271. https://doi.org/10.1016/j.cell.2020.12.014

Johnson, S. D., Hargreaves, A. L., \& Brown, M. (2006). Dark, bitter-tasting nectar functions as a filter of flower visitors in a bird-pollinated plant. Ecology, 87(11), 2709-2716. https://doi. org/10.1890/0012-9658(2006)87\%5B2709:DBNFAA\%5D2.0.CO;2

Jørgensen, K., Almaas, T. J., Marion-Poll, F., \& Mustaparta, H. (2007). Electrophysiological characterization of responses from gustatory receptor neurons of sensilla chaetica in the moth Heliothis virescens. Chemical Senses, 32(9), 863-879. https://doi.org/10.1093/ chemse/bjm057

Junca, P., Garnery, L., \& Sandoz, J. C. (2019). Genotypic trade-off between appetitive and aversive capacities in honeybees. Scientific Reports, 9(1), 1-14. https://doi.org/10.1038/s41598-019-46482-4

Junca, P., \& Sandoz, J.-C. (2015). Heat perception and aversive learning in honey bees: Putative involvement of the thermal/chemical sensor AmHsTRPA. Frontiers in Physiology, 6, 316. https://doi. org/10.3389/fphys.2015.00316

Jung, J. W., Park, K. W., Ahn, Y. J., \& Kwon, H. W. (2015). Functional characterization of sugar receptors in the western honeybee, Apis mellifera. Journal of Asia-Pacific Entomology, 18(1), 19-26. https:// doi.org/10.1016/j.aspen.2014.10.011

Kaissling, K.-E. (1987). In K. Colbow (Ed.), R. H. Wright Lectures on Insect Olfaction (pp. 1-190). Burnaby, B.C. Simon Fraser University.

Kaissling, K. E., Meng, L. Z., \& Bestmann, H. J. (1989). Responses of bombykol receptor cells to (Z, E)-4,6-hexadecadiene and linalool. Journal of Comparative Physiology A, 165(2), 147-154. https://doi. org/10.1007/BF00619189

Kaissling, K.-E., \& Thorson, J. (1980). Insect olfactory sensilla: Structural, chemical and electrical aspects of the functional organisation. In D. B. Sattelle L. M. Hall \& J. G. Hildebrand (Eds.), Receptors for Neurotransmitters, Hormones and Pheromones in Insects (pp. 261-282). Amsterdam: Elsevier/North-Holland Biomedical Press.
Kang, K., Panzano, V. C., Chang, E. C., Ni, L., Dainis, A. M., Jenkins, A. M., ... Garrity, P. A. (2012). Modulation of TRPA1 thermal sensitivity enables sensory discrimination in Drosophila. Nature, 481(7379), 76-81. https://doi.org/10.1038/nature10715

Kellenberger, S., \& Schild, L. (2002). Epithelial sodium channel/degenerin family of ion channels: A variety of functions for a shared structure. Physiological Reviews, 82(3), 735-767. https://doi. org/10.1152/physrev.00007.2002

Kessler, S. C., Tiedeken, E. J., Simcock, K. L., Derveau, S., Mitchell, J., Softley, S., ... Wright, G. A. (2015). Bees prefer foods containing neonicotinoid pesticides. Nature, 521(7550), 74-76. https://doi. org/10.1038/nature14414

Kim, S. H., Lee, Y., Akitake, B., Woodward, O. M., Guggino, W. B., \& Montell, C. (2010). Drosophila TRPA1 channel mediates chemical avoidance in gustatory receptor neurons. Proceedings of the National Academy of Sciences of the United States of America, 107(18), 8440-8445. https://doi.org/10.1073/pnas.1001425107

Kim, Y. S., \& Smith, B. H. (2000). Effect of an amino acid on feeding preferences and learning behavior in the honey bee, Apis mellifera. Journal of Insect Physiology, 46(5), 793-801. https://doi. org/10.1016/S0022-1910(99)00168-7

Knecht, Z. A., Silbering, A. F., Cruz, J., Yang, L., Croset, V., Benton, R., \& Garrity, P. A. (2017). Ionotropic receptor-dependent moist and dry cells control hygrosensation in Drosophila. eLife, 6, e26654. https://doi.org/10.7554/eLife.26654

Koh, T. W., He, Z., Gorur-Shandilya, S., Menuz, K., Larter, N. K., Stewart, S., \& Carlson, J. R. (2014). The Drosophila IR20a clade of ionotropic receptors are candidate taste and pheromone receptors. Neuron, 83(4), 850-865. https://doi.org/10.1016/j. neuron.2014.07.012

Kohno, K., Sokabe, T., Tominaga, M., \& Kadowaki, T. (2010). Honey bee thermal/chemical sensor, AmHsTRPA, reveals neofunctionalization and loss of transient receptor potential channel genes. Journal of Neuroscience, 30(37), 12219-12229. https://doi.org/10.1523/ JNEUROSCI.2001-10.2010

Kropf, J., Kelber, C., Bieringer, K., \& Rössler, W. (2014). Olfactory subsystems in the honeybee: Sensory supply and sex specificity. Cell and Tissue Research, 357(3), 583-595. https://doi.org/10.1007/ s00441-014-1892-y

Kühnholz, S., \& Seeley, T. D. (1997). The control of water collection in honey bee colonies. Behavioral Ecology and Sociobiology, 41(6), 407-422. https://doi.org/10.1007/s002650050402

Kwon, Y., Shim, H. S., Wang, X., \& Montell, C. (2008). Control of thermotactic behavior via coupling of a TRP channel to a phospholipase C signaling cascade. Nature Neuroscience, 11(8), 871-873. https:// doi.org/10.1038/nn.2170

Larsson, M. C., Domingos, A. I., Jones, W. D., Chiappe, M. E., Amrein, H., \& Vosshall, L. B. (2004). Or83b encodes a broadly expressed odorant receptor essential for Drosophila olfaction. Neuron, 43(5), 703-714. https://doi.org/10.1016/j.neuron.2004.08.019

Lau, P. W., \& Nieh, J. C. (2016). Salt preferences of honey bee water foragers. Journal of Experimental Biology, 219(6), 790-796. https:// doi.org/10.1242/jeb.132019

Lee, M. J., Sung, H. Y., Jo, H., Kim, H. W., Choi, M. S., Kwon, J. Y., \& Kang, K. J. (2017). Ionotropic receptor 76b is required for gustatory aversion to excessive $\mathrm{Na}^{+}$in Drosophila. Molecules and Cells, 40(10), 787-795. https://doi.org/10.14348/molcells.2017.0160

Lee, Y., Moon, S. J., \& Montell, C. (2009). Multiple gustatory receptors required for the caffeine response in Drosophila. Proceedings 
of the National Academy of Sciences of the United States of America, 106(11), 4495-4500. https://doi.org/10.1073/pnas.0811744106

Leung, N. Y., \& Montell, C. (2017). Unconventional roles of opsins. Annual Review of Cell and Developmental Biology, 33(1), 241-264. https://doi.org/10.1146/annurev-cellbio-100616-060432

Leung, N. Y., Thakur, D. P., Gurav, A. S., Kim, S. H., Pizio, A. D., Niv, M. Y., ... Niv, M. Y. (2020). Functions of opsins in Drosophila taste. Current Biology, 30(8), 1376-1379. https://doi.org/10.1016/ j.cub.2020.01.068

Li, Q., DeBeaubien, N. A., Sokabe, T., \& Montell, C. (2020). Temperature and sweet taste integration in Drosophila. Current Biology, 30(11), 2051-2067.e5. https://doi.org/10.1016/j.cub.2020.03.066

Liao, C., Xu, Y., Sun, Y., Lehnert, M. S., Xiang, W., Wu, J., \& Wu, Z. (2020). Feeding behavior of honey bees on dry sugar. Journal of Insect Physiology, 124, 104059. https://doi.org/10.1016/j.jinsp hys.2020.104059

Liao, L. H., Wu, W. Y., \& Berenbaum, M. R. (2017). Behavioral responses of honey bees (Apis mellifera) to natural and synthetic xenobiotics in food. Scientific Reports, 7(1), 1-8. https://doi.org/10.1038/ s41598-017-15066-5

Lim, S., Jung, J., Yunusbaev, U., Ilyasov, R., \& Kwon, H. W. (2019). Characterization and its implication of a novel taste receptor detecting nutrients in the honey bee, Apis mellifera. Scientific Reports, 9(1), 1-13. https://doi.org/10.1038/s41598-019-46738-z

Liman, E. R., Zhang, Y. V., \& Montell, C. (2014). Peripheral coding of taste. Neuron, 81(5), 984-1000. https://doi.org/10.1016/j. neuron.2014.02.022

Lin Liu, F., Jun Fu, W., Rong Yang, D. A., Peng, Y. Q., Zhang, X. W., \& He, J. Z. (2004). Reinforcement of bee-plant interaction by phenolics in food. Journal of Apicultural Research, 43(4), 155-157. https://doi.org/10.1080/00218839.2004.11101128

Ling, F., Dahanukar, A., Weiss, L. A., Kwon, J. Y., \& Carlson, J. R. (2014). The molecular and cellular basis of taste coding in the legs of Drosophila. Journal of Neuroscience, 34(21), 7148-7164. https:// doi.org/10.1523/JNEUROSCI.0649-14.2014

Liscia, A., \& Solari, P. (2000). Bitter taste recognition in the blowfly: Electrophysiological and behavioral evidence. Physiology and Behavior, 70(1-2), 61-65. https://doi.org/10.1016/S0031 -9384(00)00249-3

Liu, L., Leonard, A. S., Motto, D. G., Feller, M. A., Price, M. P., Johnson, W. A., \& Welsh, M. J. (2003). Contribution of Drosophila DEG/ENaC genes to salt taste. Neuron, 39(1), 133-146. https://doi. org/10.1016/S0896-6273(03)00394-5

Louw, G. N., \& Hadley, N. F. (1985). Water economy of the honeybee: A stoichiometric accounting. Journal of Experimental Zoology, 235(1), 147-150. https://doi.org/10.1002/jez.1402350118

Magadum, S., Banerjee, U., Murugan, P., Gangapur, D., \& Ravikesavan, R. (2013). Gene duplication as a major force in evolution. Journal of Genetics, 92(1), 155-161. https://doi.org/10.1007/s12041-013-0212-8

Matsuura, H., Sokabe, T., Kohno, K., Tominaga, M., \& Kadowaki, T. (2009). Evolutionary conservation and changes in insect TRP channels. BMC Evolutionary Biology, 9(1), 228. https://doi. org/10.1186/1471-2148-9-228

Mattila, H. R., Otis, G. W., Nguyen, L. T. P., Pham, H. D., Knight, O. M., \& Phan, N. T. (2020). Honey bees (Apis cerana) use animal feces as a tool to defend colonies against group attack by giant hornets (Vespa soror). PLOS ONE, 15(12), e0242668. https://doi. org/10.1371/journal.pone.0242668

Mercer, A. R., \& Menzel, R. (1982). Effects of biogenic amines on conditioned and unconditioned responses to olfactory stimuli in the honeybee Apis mellifera. Journal of Comparative Physiology, 145(3), 363-368. https://doi.org/10.1007/BF00619340

Meunier, N., Ferveur, J. F., \& Marion-Poll, F. (2000). Sex-specific nonpheromonal taste receptors in Drosophila. Current Biology, 10(24), 1583-1586. https://doi.org/10.1016/S0960-9822(00)00860-5

Meunier, N., Marion-Poll, F., Rospars, J.-P., \& Tanimura, T. (2003). Peripheral coding of bitter taste in Drosophila. Journal of Neurobiology, 56(2), 139-152. https://doi.org/10.1002/neu.10235

Miller, M. A., Pfeiffer, W., \& Schwartz, T. (2010). Creating the CIPRES Science Gateway for inference of large phylogenetic trees. 2010 Gateway Computing Environments Workshop, 2010 (pp. 1-8). https://doi.org/10.1109/GCE.2010.5676129

Miriyala, A., Kessler, S., Rind, F. C., \& Wright, G. A. (2018). Burst firing in bee gustatory neurons prevents adaptation. Current Biology, 28(10), 1585-1594.e3. https://doi.org/10.1016/j.cub.2018.03.070

Mitchell, B. K., Itagaki, H., \& Rivet, M. (1999). Peripheral and central structures involved in insect gustation. Microscopy Research and Technique, 47(6), 401-415. https://doi.org/10.1002/ (SICI)1097-0029(19991215)47:6<401:AID-JEMT4>3.0.CO;2-7

Miyamoto, T., \& Amrein, H. (2014). Diverse roles for the Drosophila fructose sensor Gr43a. Fly, 8(1), 19-25. https://doi.org/10.4161/ fly. 27241

Miyamoto, T., Chen, Y., Slone, J., \& Amrein, H. (2013). Identification of a Drosophila glucose receptor using $\mathrm{Ca}^{2+}$ imaging of single chemosensory neurons. PLOS ONE, 8(2), e56304. https://doi.org/10.1371/ journal.pone.0056304

Miyamoto, T., Slone, J., Song, X., \& Amrein, H. (2012). A fructose receptor functions as a nutrient sensor in the Drosophila brain. Cell, 151(5), 1113-1125. https://doi.org/10.1016/j.cell.2012.10.024

Mustard, J. A., Dews, L., Brugato, A., Dey, K., \& Wright, G. A. (2012). Consumption of an acute dose of caffeine reduces acquisition but not memory in the honey bee. Behavioural Brain Research, 232(1), 217-224. https://doi.org/10.1016/j.bbr.2012.04.014

Muth, F., Gaxiola, R. L., \& Leonard, A. S. (2020). No evidence for neonicotinoid preferences in the bumblebee Bombus impatiens. Royal Society Open Science, 7(5), 191883. https://doi.org/10.1098/ rsos. 191883

Nayak, S. V., \& Singh, R. N.(1983). Sensilla on the tarsal segments and mouthparts of adult Drosophila melanogaster meigen (Diptera: Drosophilidae). International Journal of Insect Morphology and Embryology, 12(5-6), 273-291. https://doi.org/10.1016/0020-7322(83)90023-5

Negri, I., Mavris, C., Di Prisco, G., Caprio, E., \& Pellecchia, M. (2015). Honey bees (Apis mellifera, L.) as active samplers of airborne particulate matter. PLoS ONE, 10(7), e0132491. https://doi.org/10.1371/ journal.pone.0132491

Ni, L., Klein, M., Svec, K. V., Budelli, G., Chang, E. C., Ferrer, A. J., ... Garrity, P. A. (2016). The ionotropic receptors IR21a and IR25a mediate cool sensing in Drosophila. eLife, 5, e13254. https://doi. org/10.7554/eLife. 13254

Nicolson, S. W. (2009). Water homeostasis in bees, with the emphasis on sociality. Journal of Experimental Biology, 212(3), 429-434. https://doi.org/10.1242/jeb.022343

Oka, Y., Butnaru, M., Von Buchholtz, L., Ryba, N. J. P., \& Zuker, C. S. (2013). High salt recruits aversive taste pathways. Nature, 494(7438), 472-475. https://doi.org/10.1038/nature11905

Oldroyd, B. P. (2007). What's killing American honey bees? PLoS Biology, 5(6), 1195-1199. https://doi.org/10.1371/journ al.pbio.0050168

Olsson, S. B., \& Hansson, B. S. (2013). Electroantennogram and single sensillum recording in insect antennae. Methods in Molecular 
Biology, 1068, 157-177. https://doi.org/10.1007/978-1-62703 -619-1_11

Paerhati, Y., Ishiguro, S., Ueda-Matsuo, R., Yang, P., Yamashita, T., Ito, K., Maekawa, H., Tani, H., \& Suzuki, K. (2015). Expression of AmGR10 of the gustatory receptor family in honey bee is correlated with nursing behavior. PLoS ONE, 10(11), e0142917. https://doi. org/10.1371/journal.pone.0142917

Page, R. E., \& Erber, J. (2002). Levels of behavioral organization and the evolution of division of labor. Naturwissenschaften, 89(3), 91106. https://doi.org/10.1007/s00114-002-0299-x

Pankiw, T., \& Page, R. E. (1999). The effect of genotype, age, sex, and caste on response thresholds to sucrose and foraging behavior of honey bees (Apis mellifera L.). Journal of Comparative Physiology A: Sensory, Neural, and Behavioral Physiology, 185(2), 207-213. https://doi.org/10.1007/s003590050379

Pankiw, T., Waddington, K. D., \& Page, R. E. (2001). Modulation of sucrose response thresholds in honey bees (Apis mellifera L.): Influence of genotype, feeding, and foraging experience. Journal of Comparative Physiology A, 187(4), 293-301. https://doi. org/10.1007/s003590100201

Paoli, M., \& Galizia, G. C. (2021). Olfactory coding in honeybees. Cell and Tissue Research, 1-24. https://doi.org/10.1007/s00441-02003385-5

Paoli, P. P., Donley, D., Stabler, D., Saseendranath, A., Nicolson, S. W., Simpson, S. J., \& Wright, G. A. (2014). Nutritional balance of essential amino acids and carbohydrates of the adult worker honeybee depends on age. Amino Acids, 46(6), 1449-1458. https://doi. org/10.1007/s00726-014-1706-2

Pisa, L. W., Amaral-Rogers, V., Belzunces, L. P., Bonmatin, J. M., Downs, C. A., Goulson, D., Kreutzweiser, D. P., Krupke, C., Liess, M., McField, M., Morrissey, C. A., Noome, D. A., Settele, J., Simon-Delso, N., Stark, J. D., Van der Sluijs, J. P., Van Dyck, H., \& Wiemers, M. (2014). Effects of neonicotinoids and fipronil on nontarget invertebrates. Environmental Science and Pollution Research, 22(1), 68-102. https://doi.org/10.1007/s11356-014-3471-x

Pophof, B. (2002). Octopamine enhances moth olfactory responses to pheromones, but not those to general odorants. Journal of Comparative Physiology A, 188(8), 659-662. https://doi. org/10.1007/s00359-002-0343-5

Rimal, S., \& Lee, Y. (2018). The multidimensional ionotropic receptors of Drosophila melanogaster. Insect Molecular Biology, 27(1), 1-7. https://doi.org/10.1111/imb.12347

Rimal, S., Sang, J., Poudel, S., Thakur, D., Montell, C., \& Lee, Y. (2019). Mechanism of acetic acid gustatory repulsion in Drosophila. Cell Reports, 26(6), 1432-1442. https://doi.org/10.1016/j. celrep.2019.01.042

Robertson, H. M., \& Wanner, K. W. (2006). The chemoreceptor superfamily in the honey bee, Apis mellifera: Expansion of the odorant, but not gustatory, receptor family. Genome Research, 16(11), 13951403. https://doi.org/10.1101/gr.5057506

Robertson, H. M., Warr, C. G., \& Carlson, J. R. (2003). Molecular evolution of the insect chemoreceptor gene superfamily in Drosophila melanogaster. Proceedings of the National Academy of Sciences of the United States of America, 100(24), 14537-14542. https://doi. org/10.1073/pnas.2335847100

Robinson, G. E., Underwood, B. A., Henderson, C. E., \& Henderson, C. E. (1984). A highly specialized water-collecting honey bee. Apidologie, 15(3), 355-358. https://doi.org/10.1051/apido:19840307

Rytz, R., Croset, V., \& Benton, R. (2013). Ionotropic receptors (IRs): Chemosensory ionotropic glutamate receptors in Drosophila and beyond. Insect Biochemistry and Molecular Biology, 43(9), 888897. https://doi.org/10.1016/j.ibmb.2013.02.007

Sadd, B. M., Barribeau, S. M., Bloch, G., de Graaf, D. C., Dearden, P., Elsik, C. G., Gadau, J., Grimmelikhuijzen, C. J. P., Hasselmann, M., Lozier, J. D., Robertson, H. M., Smagghe, G., Stolle, E., Van Vaerenbergh, M., Waterhouse, R. M., Bornberg-Bauer, E., Klasberg, S., Bennett, A. K., Câmara, F., ... Worley, K. C. (2015). The genomes of two key bumblebee species with primitive eusocial organization. Genome Biology, 16(1), 1-32. https://doi.org/10.1186/ s13059-015-0623-3

Sanchez-Bayo, F., \& Goka, K. (2014). Pesticide residues and bees - A risk assessment. PLOS ONE, 9(4), e94482. https://doi.org/10.1371/ journal.pone.0094482

Sandoz, J. C. (2011). Behavioral and neurophysiological study of olfactory perception and learning in honeybees. Frontiers in Systems Neuroscience, 5, 98. https://doi.org/10.3389/fnsys.2011.00098

Sato, K., Tanaka, K., \& Touhara, K. (2011). Sugar-regulated cation channel formed by an insect gustatory receptor. Proceedings of the National Academy of Sciences of the United States of America, 108(28), 11680-11685. https://doi.org/10.1073/pnas.1019622108

Scheiner, R., \& Arnold, G. (2010). Effects of patriline on gustatory responsiveness and olfactory learning in honey bees. Apidologie, 41(1), 29-37. https://doi.org/10.1051/apido/2009040

Scheiner, R., Baumann, A., \& Blenau, W. (2006). Aminergic control and modulation of honeybee behaviour. Current Neuropharmacology, 4(4), 259-276. https://doi.org/10.2174/157015906778520791

Scheiner, R., Page, R. E., \& Erber, J. (2004). Sucrose responsiveness and behavioral plasticity in honey bees (Apis mellifera). Apidologie, 35(2), 133-142. https://doi.org/10.1051/apido:2004001

Scheiner, R., Plückhahn, S., Öney, B., Blenau, W., \& Erber, J. (2002). Behavioural pharmacology of octopamine, tyramine and dopamine in honey bees. Behavioural Brain Research, 136(2), 545-553. https://doi.org/10.1016/S0166-4328(02)00205-X

Scheiner, R., Reim, T., Søvik, E., Entler, B. V., Barron, A. B., \& Thamm, M. (2017). Learning, gustatory responsiveness and tyramine differences across nurse and forager honeybees. Journal of Experimental Biology, 220(8), 1443-1450. https://doi.org/10.1242/jeb.152496

Scheiner, R., Schnitt, S., \& Erber, J. (2005). The functions of antennal mechanoreceptors and antennal joints in tactile discrimination of the honeybee (Apis mellifera L.). Journal of Comparative Physiology A, 191(9), 857-864. https://doi.org/10.1007/s00359-005-0009-1

Schneider, D., \& Hecker, E. (1956). Zur Elektrophysiologie der Antenne des Seidenspinners Bombyx mori bei Reizung mit angereicherten Extrakten des Sexuallockstoffes. Zeitschrift Fur Naturforschung B, 11(3), 121-124. https://doi.org/10.1515/znb-1956-0301

Schoonhoven, L. M., \& van Loon, J. J. A. (2002). An inventory of taste in caterpillars: Each species its own key. Acta Zoologica Academiae Scientiarum Hungaricae, 48(Suppl 1), 215-263.

Schulz, D. J., Barron, A. B., \& Robinson, G. E. (2002). A role for octopamine in honey bee division of labor. Brain, Behavior and Evolution, 60(6), 350-359. https://doi.org/10.1159/000067788

Scott, K. (2018). Gustatory processing in Drosophila melanogaster. Annual Review of Entomology, 63, 15-30. https://doi.org/10.1146/ annurev-ento-020117-043331

Scott, K., Brady, R., Cravchik, A., Morozov, P., Rzhetsky, A., Zuker, C., \& Axel, R. (2001). A chemosensory gene family encoding candidate gustatory and olfactory receptors in Drosophila. Cell, 104(5), 661673. https://doi.org/10.1016/S0092-8674(01)00263-X

Sellier, M.-J., Reeb, P., \& Marion-Poll, F. (2011). Consumption of bitter alkaloids in Drosophila melanogaster in multiple-choice 
test conditions. Chemical Senses, 36(4), 323-334. https://doi. org/10.1093/chemse/bjq133

Si Quang, L., Gascuel, O., \& Lartillot, N. (2008). Empirical profile mixture models for phylogenetic reconstruction. Bioinformatics, 24(20), 2317-2323. https://doi.org/10.1093/bioinformatics/btn445

Simcock, N. K., Wakeling, L. A., Ford, D., \& Wright, G. A. (2017). Effects of age and nutritional state on the expression of gustatory receptors in the honeybee (Apis mellifera). PLoS ONE, 12(4), e0175158. https://doi.org/10.1371/journal.pone.0175158

Simpson, S. J., \& Simpson, C. L. (1992). Mechanisms controlling modulation by haemolymph amino acids of gustatory responsiveness in the locust. Journal of Experimental Biology, 168(1), 269-287. https://doi.org/10.1242/JEB.168.1.269

Singaravelan, N., Nee'man, G., Inbar, M., \& Izhaki, I. (2005). Feeding responses of free-flying honeybees to secondary compounds mimicking floral nectars. Journal of Chemical Ecology, 31(12), 27912804. https://doi.org/10.1007/s10886-005-8394-z

Slone, J., Daniels, J., \& Amrein, H. (2007). Sugar receptors in Drosophila. Current Biology, 17(20), 1809-1816. https://doi. org/10.1016/j.cub.2007.09.027

Smith, C. D., Zimin, A., Holt, C., Abouheif, E., Benton, R., Cash, E., Croset, V., Currie, C. R., Elhaik, E., Elsik, C. G., Fave, M.J., Fernandes, V., Gadau, J., Gibson, J. D., Graur, D., Grubbs, K. J., Hagen, D. E., Helmkampf, M., Holley, J.-A., ... Tsutsui, N. D. (2011). Draft genome of the globally widespread and invasive Argentine ant (Linepithema humile). Proceedings of the National Academy of Sciences of the United States of America, 108(14), 5673-5678. https://doi.org/10.1073/pnas.1008617108

Snordgrass, R. E. (1956). Anatomy of the honey bee. Cornell University Press.

Sollai, G., Biolchini, M., \& Crnjar, R. (2018). Taste sensitivity and divergence in host plant acceptance between adult females and larvae of Papilio hospiton. Insect Science, 25(5), 809-822. https://doi. org/10.1111/1744-7917.12581

Sollai, G., \& Crnjar, R. (2019). The contribution of gustatory input to larval acceptance and female oviposition choice of potential host plants in Papilio hospiton (Géné). Archives of Insect Biochemistry and Physiology, 100(1), e21521. https://doi.org/10.1002/arch.21521

Søvik, E., Perry, C. J., LaMora, A., Barron, A. B., \& Ben-Shahar, Y. (2015). Negative impact of manganese on honeybee foraging. Biology Letters, 11(3), 20140989. https://doi.org/10.1098/ rsbl.2014.0989

Stamatakis, A. (2014). RAxML version 8: A tool for phylogenetic analysis and post-analysis of large phylogenies. Bioinformatics, 30(9), 1312-1313. https://doi.org/10.1093/bioinformatics/btu033

Starostina, E., Liu, T., Vijayan, V., Zheng, Z., Siwicki, K. K., \& Pikielny, C. W. (2012). A Drosophila DEG/ENaC subunit functions specifically in gustatory neurons required for male courtship behavior. Journal of Neuroscience, 32(13), 4665-4674. https://doi. org/10.1523/JNEUROSCI.6178-11.2012

Stocker, R. F. (1994). The organization of the chemosensory system in Drosophila melanogaster: A rewiew. Cell and Tissue Research, 275(1), 3-26. https://doi.org/10.1007/BF00305372

Stocker, R. F. (2004). Taste perception: Drosophila - A model of good taste. Current Biology, 14(14), R560-R561. https://doi. org/10.1016/j.cub.2004.07.011

Stoffolano, J. G., Schauber, E., Yin, C. M., Tillman, J. A., \& Blomquist, G. J. (1997). Cuticular hydrocarbons and their role in copulatory behavior in Phormia regina (Meigen). Journal of Insect Physiology,
43(11), 1065-1076. https://doi.org/10.1016/S0022-1910(97)00050 $-4$

Szczęsna, T. (2006). Protein content and amino acid composition of bee-collected pollen from selected botanical origins. Journal of Apicultural Science, 50(2), 91-99.

Takada, T., Sasaki, T., Sato, R., Kikuta, S., \& Inoue, M. N. (2018). Differential expression of a fructose receptor gene in honey bee workers according to age and behavioral role. Archives of Insect Biochemistry and Physiology, 97(2), e21437. https://doi. org/10.1002/arch.21437

Tanimura, T., \& Shimada, I. (1981). Multiple receptor proteins for sweet taste in Drosophila discriminated by papain treatment. Journal of Comparative Physiology A, 141(2), 265-269. https://doi. org/10.1007/BF01342672

Taylor, D. J., Robinson, G. E., Logan, B. J., Laverty, R., \& Mercer, A. R. (1992). Changes in brain amine levels associated with the morphological and behavioural development of the worker honeybee. Journal of Comparative Physiology A, 170(6), 715-721. https://doi. org/10.1007/BF00198982

Tedjakumala, S. R., Aimable, M., \& Giurfa, M. (2014). Pharmacological modulation of aversive responsiveness in honey bees. Frontiers in Behavioral Neuroscience, 7, 221. https://doi.org/10.3389/ fnbeh.2013.00221

Thompson, J. D., Higgins, D. G., \& Gibson, T. J. (1994). CLUSTAL W: Improving the sensitivity of progressive multiple sequence alignment through sequence weighting, position-specific gap penalties and weight matrix choice. Nucleic Acids Research, 22(22), 46734680. https://doi.org/10.1093/nar/22.22.4673

Thorne, N., Chromey, C., Bray, S., \& Amrein, H. (2004). Taste perception and coding in Drosophila. Current Biology, 14(12), 1065-1079. https://doi.org/10.1016/j.cub.2004.05.019

Tsuruda, J. M., \& Page, R. E. (2009). The effects of foraging role and genotype on light and sucrose responsiveness in honey bees (Apis mellifera L.). Behavioural Brain Research, 205(1), 132-137. https:// doi.org/10.1016/j.bbr.2009.07.022

vanEngelsdorp D., Evans J. D., Saegerman C., Mullin C., Haubruge E., Nguyen B. K., Frazier M., Frazier J., Cox-Foster D., Chen Y., Underwood R., Tarpy D. R., \& Pettis J. S. (2009). Colony Collapse Disorder: A Descriptive Study. PLoS ONE, 4(8), e6481. http://dx. doi.org/10.1371/journal.pone.0006481

Velarde, R. A., Sauer, C. D., Walden, K. K. O., Fahrbach, S. E., \& Robertson, H. M. (2005). Pteropsin: A vertebrate-like non-visual opsin expressed in the honey bee brain. Insect Biochemistry and Molecular Biology, 35(12), 1367-1377. https://doi.org/10.1016/j. ibmb.2005.09.001

Viswanath, V., Story, G. M., Peier, A. M., Petrus, M. J., Lee, V. M., Hwang, S. W., ... Tim, J. (2003). Opposite thermosensor in fruitfly and mouse. Nature, 423(6942), 822-823. https://doi. org/10.1038/423822a

von Frisch, K. (1934). Über den Geschmackssinn der Biene - Ein Beitrag zur vergleichenden Physiologie des Geschmacks. Zeitschrift Für Vergleichende Physiologie, 21(1), 1-156. https://doi.org/10.1007/ BF00338271

von Frisch, K. (1967). The Dance Language and Orientation of Bees (pp. 1-566). Cambridge, Massachusetts: Belknap Press.

Vosshall, L. B., \& Stocker, R. F. (2007, June 28). Molecular architecture of smell and taste in Drosophila. Annual Review of Neuroscience, 30(8), 505-533. https://doi.org/10.1146/annur ev.neuro.30.051606.094306 
Wakakuwa, M., Kurasawa, M., Giurfa, M., \& Arikawa, K. (2005). Spectral heterogeneity of honeybee ommatidia. Naturwissenschaften, 92(10), 464-467. https://doi.org/10.1007/s00114-005-0018-5

Waller, G. D. (1972). Evaluating responses of honey bees to sugar solutions using an artificial-flower feeder. Annals of the Entomological Society of America, 65(4), 857-862. https://doi.org/10.1093/aesa/65.4.857

Wang, G., Qiu, Y. T., Lu, T., Kwon, H.-W., Jason Pitts, R., Van Loon, J. J. A., ... Zwiebel, L. J. (2009). Anopheles gambiae TRPA1 is a heat-activated channel expressed in thermosensitive sensilla of female antennae. European Journal of Neuroscience, 30(6), 967-974. https://doi.org/10.1111/j.1460-9568.2009.06901.x

Wang, Y., Baker, N., \& Amdam, G. V. (2013). RNAi-mediated double gene knockdown and gustatory perception measurement in honey bees (Apis mellifera). Journal of Visualized Experiments: Jove, 77, 50446. https://doi.org/10.3791/50446

Wang, Z., Singhvi, A., Kong, P., \& Scott, K. (2004). Taste representations in the Drosophila brain. Cell, 117(7), 981-991. https://doi. org/10.1016/j.cell.2004.06.011

Weiss, L. A., Dahanukar, A., Kwon, J. Y., Banerjee, D., \& Carlson, J. R. (2011). The molecular and cellular basis of bitter taste in Drosophila. Neuron, 69(2), 258-272. https://doi.org/10.1016/j. neuron.2011.01.001

Whitehead, A. T. (1978). Electrophysiological response of honey bee labial palp contact chemoreceptors to sugars and electrolytes. Physiological Entomology, 3(3), 241-248. https://doi.org/10.1111/ j.1365-3032.1978.tb00153.x

Whitehead, A. T., \& Larsen, J. R. (1976a). Ultrastructure of the contact chemoreceptors of Apis mellifera L. (Hymenoptera: Apidae). International Journal of Insect Morphology and Embryology, 5(45), 301-315. https://doi.org/10.1016/0020-7322(76)90030-1

Whitehead, A. T., \& Larsen, J. R. (1976b). Electrophysiological responses of galeal contact chemoreceptors of Apis mellifera to selected sugars and electrolytes. Journal of Insect Physiology, 22(12), 1609-1616. https://doi.org/10.1016/0022-1910(76)90052-4

Wisotsky, Z., Medina, A., Freeman, E., \& Dahanukar, A. (2011). Evolutionary differences in food preference rely on Gr64e, a receptor for glycerol. Nature Neuroscience, 14(12), 1534-1541. https:// doi.org/10.1038/nn.2944
Wright, G. A., Baker, D. D., Palmer, M. J., Stabler, D., Mustard, J. A., Power, E. F., ... Stevenson, P. C. (2013). Caffeine in floral nectar enhances a pollinator's memory of reward. Science, 339(6124), 1202 1204. https://doi.org/10.1126/science.1228806

Wright, G. A., Mustard, J. A., Simcock, N. K., Ross-Taylor, A. A. R., McNicholas, L. D., Popescu, A., \& Marion-Poll, F. (2010). Parallel reinforcement pathways for conditioned food aversions in the honeybee. Current Biology, 20(24), 2234-2240. https://doi.org/10.1016/ j.cub.2010.11.040

Wykes, G. R. (1952). The preferences of honeybees for solutions of various sugars which occur in nectar. Journal of Experimental Biology, 29(4), 511-519. https://doi.org/10.1242/jeb.29.4.511

$\mathrm{Xu}, \mathrm{W}$. (2020). How do moth and butterfly taste?-Molecular basis of gustatory receptors in Lepidoptera. Insect Science, 27(6), 11481157. https://doi.org/10.1111/1744-7917.12718

Zhang, Y. V., Ni, J., \& Montell, C. (2013). The molecular basis for attractive salt-taste coding in Drosophila. Science, 340(6138), 13341338. https://doi.org/10.1126/science.1234133

Zhong, L., Bellemer, A., Yan, H., Honjo, K., Robertson, J., Hwang, R. Y., Pitt, G. S., \& Tracey, W. D. (2012). Thermosensory and nonthermosensory isoforms of Drosophila melanogaster TRPA1 reveal heat-sensor domains of a thermoTRP channel. Cell Reports, 1(1), 43-55. https://doi.org/10.1016/j.celrep.2011.11.002

\section{SUPPORTING INFORMATION}

Additional supporting information may be found online in the Supporting Information section.

How to cite this article: Bestea L, Réjaud A, Sandoz J-C, Carcaud J, Giurfa M, de Brito Sanchez MG.

Peripheral taste detection in honey bees: What do taste receptors respond to?. Eur J Neurosci. 2021;00:1-28. https://doi.org/10.1111/ejn.15265 